\title{
Efficacy Loss of the Anticonvulsant Carbamazepine in Mice Lacking Sodium Channel $\beta$ Subunits via Paradoxical Effects on Persistent Sodium Currents
}

\author{
Mischa Uebachs, ${ }^{1}$ Thoralf Opitz, ${ }^{1}$ Michel Royeck, ${ }^{1,2}$ Gesa Dickhof, ${ }^{1}$ Marie-Therese Horstmann, ${ }^{1,3,4}$ Lori L. Isom, ${ }^{5}$ \\ and Heinz Beck ${ }^{1}$ \\ ${ }^{1}$ Department of Epileptology, University of Bonn Medical Center, 53105 Bonn, Germany, ${ }^{2}$ Department of Neurosurgery, University of Bonn Medical Center, \\ 53105 Bonn, Germany, ${ }^{3}$ Helmholtz Institute for Radiation and Nuclear Physics, University of Bonn, 53115 Bonn, Germany, ${ }^{4}$ Interdisciplinary Center for \\ Complex Systems, University of Bonn, 53117 Bonn, Germany, and ${ }^{5}$ Department of Pharmacology, University of Michigan, 48109-0632
}

\begin{abstract}
Neuronal excitability is critically determined by the properties of voltage-gated $\mathrm{Na}^{+}$currents. Fast transient $\mathrm{Na}^{+}$currents $\left(I_{\mathrm{NaT}}\right)$ mediate the fast upstroke of action potentials, whereas low-voltage-activated persistent $\mathrm{Na}^{+}$currents $\left(I_{\mathrm{NaP}}\right)$ contribute to subthreshold excitation. $\mathrm{Na}^{+}$channels are composed of a pore-forming $\alpha$ subunit and $\beta$ subunits, which modify the biophysical properties of $\alpha$ subunits. We have examined the idea that the presence of $\beta$ subunits also modifies the pharmacological properties of the $\mathrm{Na}^{+}$channel complex using mice lacking either the $\beta_{1}(S c n 1 b)$ or $\beta_{2}$ (Scn2b) subunit. Classical effects of the anticonvulsant carbamazepine (CBZ), such as the use-dependent reduction of $I_{\mathrm{NaT}}$ and effects on $I_{\mathrm{NaT}}$ voltage dependence of inactivation, were unaltered in mice lacking $\beta$ subunits. Surprisingly, CBZ induced a small but significant shift of the voltage dependence of activation of $I_{\mathrm{NaT}}$ and $I_{\mathrm{NaP}}$ to more hyperpolarized potentials. This novel CBZ effect on $I_{\mathrm{NaP}}$ was strongly enhanced in $S c n 1 b$ null mice, leading to a pronounced increase of $I_{\mathrm{NaP}}$ within the subthreshold potential range, in particular at low CBZ concentrations of 10-30 $\mu \mathrm{m}$. A combination of current-clamp and computational modeling studies revealed that this effect causes a complete loss of $\mathrm{CBZ}$ efficacy in reducing repetitive firing. Thus, $\beta$ subunits modify not only the biophysical but also the pharmacological properties of $\mathrm{Na}^{+}$channels, in particular with respect to $I_{\mathrm{NaP}}$. Consequently, altered expression of $\beta$ subunits in other neurological disorders may cause altered neuronal sensitivity to drugs targeting $\mathrm{Na}^{+}$channels.
\end{abstract}

\section{Introduction}

Voltage-gated $\mathrm{Na}^{+}$channels are present in all excitable cells and play a crucial role in action potential generation and propagation. They are composed of a pore-forming $\alpha$ subunit and one or two $\beta$ subunits (Catterall, 1999). The $\beta_{1}$ and $\beta_{2}$ subunits are intriguing because they are capable of serving as cell adhesion molecules, regulate the surface expression and trafficking of channels, and modify the biophysical properties of the pore-forming $\alpha$ subunits (Isom, 2001). $\beta_{1}$ subunits exhibit an extracellular Ig-like domain, which enables it to mediate diverse functions, including cell-cell interactions, axonal outgrowth, and neuronal migration (Brackenbury and Isom, 2008).

In addition, $\beta_{1}$ subunits have been implicated in trafficking and targeting of channels to specific neuronal compartments (Brackenbury et al., 2010). $\beta$ subunits also exert powerful modulatory effects on the biophysical properties of $\mathrm{Na}^{+}$channel $\alpha$

\footnotetext{
Received March 25, 2010; revised April 28, 2010; accepted May 11, 2010.

This work was supported by the Deutsche Forschungsgemeinschaft (SFB TR3, LE660/4-1), Nationales Genomforschungsnetzwerk NGFN plus EmiNet, EPICURE, and the BONFOR program of the University of Bonn Medical Center.

Correspondence should be addressed to Prof. Dr. Heinz Beck, Laboratory of Experimental Epileptology, Department of Epileptology, University of Bonn, Sigmund-Freud-Straße 25, 53105 Bonn, Germany. E-mail: heinz.beck@ ukb.uni-bonn.de.

DOI:10.1523/JNEUROSCI.1534-10.2010

Copyright $\odot 2010$ the authors $\quad 0270-6474 / 10 / 308489-13 \$ 15.00 / 0$
}

subunits. These effects have been studied extensively by coexpression of pore-forming and accessory subunits in various expression systems. The functional effects of $\beta$ subunit coexpression have proven quite diverse. Coexpression of $\beta$ subunits modulates the activation and inactivation time course as well as the time course of recovery from fast inactivation of pore-forming subunits. Additionally, $\beta$ subunits also affect the voltage dependence of activation and inactivation. These effects appear to be strongly dependent on the cellular model used for the experiments, indicating that the interaction of $\alpha$ and $\beta$ subunits may be a strongly modulated process (Toib et al., 1998; Qu et al., 2001; Meadows et al., 2002; Xu et al., 2007). While there is debate regarding the precise nature of these effects, it is clear that $\beta$ subunits powerfully modulate the biophysical properties and localization of $\mathrm{Na}^{+}$channel $\alpha$ subunits.

In the present study, we have now elected to investigate how the presence of $\beta$ subunits affects the pharmacology of $\mathrm{Na}^{+}$ channels. The $\mathrm{Na}^{+}$channel complex is an important drug target, i.e., for drugs used in the treatment of both epilepsy and neuropathic pain. It is largely unclear how the subunit composition, and in particular the presence of $\beta$ subunits, affects drug sensitivity of $\mathrm{Na}^{+}$channel complexes. Intriguingly, a $S c n 1 b$ mutation has been shown to affect the response of $\mathrm{Na}^{+}$channels to phenytoin (Lucas et al., 2005). This suggests that the presence of $\beta$ subunits may affect the response of the $\mathrm{Na}^{+}$channel complex to 
anticonvulsant drugs. In the present study, we have therefore examined how ablating expression of $S c n 1 b$ or $S c n 2 b$ in native hippocampal neurons affects the CBZ response of $\mathrm{Na}^{+}$channels and how this impacts anticonvulsant effects on neuronal excitability.

\section{Materials and Methods}

Scn $1 \mathrm{~b}$ - and Scn2b-null mice. The generation of $S c n 1 b$ or $S c n 2 b$-null mice has been previously described (Chen et al., 2002, 2004). Animals used in this study were bred from congenic $S c n 1 b^{+/-}$or Scn $2 b^{+/-}$mice of generation N10 or higher bred on the C57BL/6 genetic background. Experiments were performed on slices or dissociated neurons from the hippocampus of male $S c n 1 b$ or $S c n 2 b$ null mice and their wild-type littermates. Experiments on $S c n 1 b$ null mice and wild-type littermates were performed at postnatal days 12-20 (P12-P20) because $S c n 1 b$ null mice die at approximately P20 (Chen et al., 2004). Recordings from Scn $2 b$ null animals and littermates were performed at P40-P60. All animal experiments were performed in accordance with the regulations of the local animal care and use committee.

Preparation of brain slices and dissociated hippocampal neurons. Acutely dissociated CA1 and DG neurons were harvested from wildtype or littermate null mice. Animals were perfused through the heart under deep anesthesia (ketamine $100 \mathrm{mg} / \mathrm{kg}$, xylazine $15 \mathrm{mg} / \mathrm{kg}$ ) with ice-cold sucrose-based artificial CSF (ACSF) comprising (in $\mathrm{mm}$ ): $60 \mathrm{NaCl}, 110$ sucrose, 26 $\mathrm{NaHCO}_{3}, 2.5 \mathrm{KCl}, 1.25 \mathrm{NaH}_{2} \mathrm{PO}_{4}, 5 \mathrm{MgCl}_{2}, 1$ $\mathrm{CaCl}_{2}$, and 25 glucose, $\mathrm{pH} 7.4$ adjusted with $\mathrm{NaOH}$, osmolality $305 \mathrm{mOsm}$. Subsequently the brain was rapidly removed. Transverse hippocampal slices $(400 \mu \mathrm{m})$ were prepared with a vibrating microslicer (Microm) and then transferred to a storage chamber filled with carbogenated sucrose ACSF $\left(95 \% \mathrm{O}_{2}, 5 \%\right.$ $\mathrm{CO}_{2}$ ). The chamber was gradually warmed to $36^{\circ} \mathrm{C}$ in a water bath and maintained at this temperature for $\sim 30 \mathrm{~min}$. Finally, the slices were transferred into a chamber filled with ACSF containing the following (in $\mathrm{mM}$ ): 125

$\mathrm{NaCl}, 2.5 \mathrm{KCl}, 1 \mathrm{MgCl}_{2}, 2 \mathrm{CaCl}_{2}, 26 \mathrm{NaHCO}_{3}, 1.25 \mathrm{NaH}_{2} \mathrm{PO}_{4}$, and 25 glucose, pH 7.4 adjusted with $\mathrm{NaOH}$, osmolality $305 \mathrm{mOsm}$, where they were maintained at room temperature for an equilibration period of at least $60 \mathrm{~min}$. Subsequently, they were either used for preparation of dissociated neurons (see below) or transferred to an interface chamber for sharp microelectrode recordings.

For dissociation, slices were retrieved from the storage chamber (up to $5 \mathrm{~h}$ after preparation) and transferred one at a time to a tube with $5 \mathrm{ml}$ of saline containing the following (in $\mathrm{mM}$ ): 145 methanesulfonic acid sodium salt $\left(\mathrm{CH}_{3} \mathrm{SO}_{3} \mathrm{Na}\right), 3 \mathrm{KCl}, 1 \mathrm{MgCl}_{2}, 0.5 \mathrm{CaCl}_{2}, 10 \mathrm{HEPES}$, and 15 glucose, pH 7.4 adjusted with $\mathrm{NaOH}$, osmolality $308 \mathrm{mOsm}$. Pronase (protease type XIV, $2 \mathrm{mg} / \mathrm{ml}$, Sigma) was added to the oxygenated medium $\left(100 \% \mathrm{O}_{2}\right)$. After an incubation period of $12 \mathrm{~min}$ at $36^{\circ} \mathrm{C}$ and a subsequent period of $10 \mathrm{~min}$ at room temperature, the slice was washed in Pronase-free saline of an identical composition. The CA1 or the DG region was dissected and triturated with fire-polished glass pipettes of decreasing aperture. The Petri dish containing the cell suspension was then mounted on the stage of an inverted microscope (Axiovert 100, Zeiss). Dissociated cells were allowed to settle for 5-10 min before recordings were attempted. Whole-cell recordings were performed only on

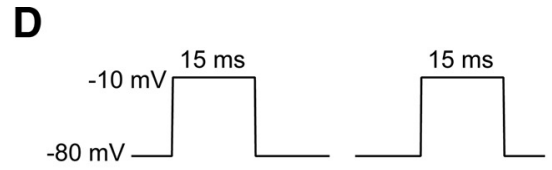

E

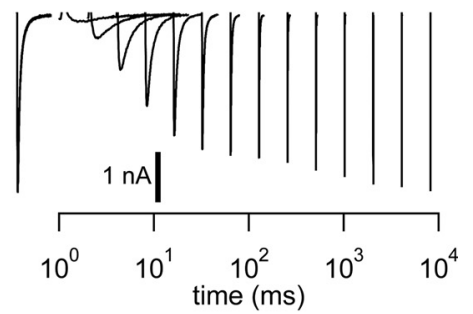

$\mathbf{F}$

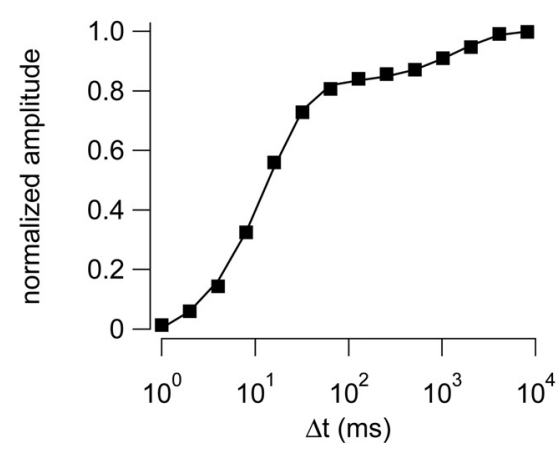

Figure 1. Analysis of $I_{\mathrm{NaT}}$ properties. $A-C$, Analysis of the voltage dependence of activation and inactivation in a representative neuron. $A$, Voltage protocol used to analyze voltage dependence of $I_{\mathrm{NaT}}$, with pulses to potentials ranging from $-100 \mathrm{mV}$ to +10 (500 ms) followed by a voltage step to $-10 \mathrm{mV}(15 \mathrm{~ms})$. The break in the lines indicates a gap of $485 \mathrm{~ms}$. $\boldsymbol{B}$, The initial $500 \mathrm{~ms}$ subsequent voltage step to $-10 \mathrm{mV}$ allowed us to assess voltage-dependent inactivation by the preceding voltage step (reprerectivation was determined with a second voltage step to $-10 \mathrm{mV}$. E, Representative recording of recovery from the peak amplitude $I_{\text {NaT }}$ during the initial voltage step to $-10 \mathrm{mV}$. A biexponential fit is superimposed as solid line. Exemplary analysis is shown for the recordings shown in $\boldsymbol{E}$. For the quantitative average values for all experimental groups, see Table 1.

morphologically identified neurons with a smooth surface and a threedimensional contour.

Patch-clamp recordings. Properties of $I_{\mathrm{NaT}}$ were examined in dissociated DG neurons, which were superfused with an extracellular solution containing the following (in $\mathrm{mm}$ ): $40 \mathrm{CH}_{3} \mathrm{SO}_{3} \mathrm{Na}, 90$ tetraethylammonium (TEA), $1.6 \mathrm{CaCl}_{2}, 2 \mathrm{MgCl}_{2}, 10$ HEPES, 5 4-aminopyridine, 0.2 $\mathrm{CdCl}_{2}$, and 15 glucose, pH 7.4 adjusted with $\mathrm{NaOH}$, osmolality 315 mOsm. Patch pipettes (resistance: $3-4 \mathrm{M} \Omega$ ) were filled with an intracellular solution containing the following (in $\mathrm{mm}$ ): $110 \mathrm{CsF}, 20 \mathrm{TEA}, 2$ $\mathrm{MgCl}_{2}, 10$ HEPES, 11 EGTA, 5 ATP, and 0.5 GTP, pH 7.2 adjusted with $\mathrm{CsOH}$, osmolality $300 \mathrm{mOsm}$. Experiments on $I_{\mathrm{NaP}}$ were performed on dissociated CA1 neurons. Recordings were performed using an extracellular solution containing the following (in $\mathrm{mM}$ ): $100 \mathrm{CH}_{3} \mathrm{SO}_{3} \mathrm{Na}, 40 \mathrm{TEA}$, $2 \mathrm{CaCl}_{2}, 3 \mathrm{MgCl}_{2}, 10$ HEPES, 5 4-aminopyridine, $0.2 \mathrm{CdCl}_{2}$, and 25 glucose, pH 7.4 adjusted with $\mathrm{NaOH}$, osmolality $315 \mathrm{mOsm}$. CBZ was applied by hydrostatic pressure via a nearby $(50-100 \mu \mathrm{m})$ superfusion pipette. Solutions around the neurons were exchanged within $<1 \mathrm{~min}$. The intracellular solution for recordings of $I_{\mathrm{NaP}}$ contained (in mM) 110 CsF, $2 \mathrm{MgCl}_{2}, 10$ HEPES, 11 EGTA, 2 ATP, and 0.5 GTP, pH 7.2 adjusted with $\mathrm{CsOH}$, osmolality $300 \mathrm{mOsm}$. A liquid-junction potential of -10 
Table 1. Properties of transient $\mathrm{Na}^{+}$currents in $\mathrm{Sen} 1 b$ and $\mathrm{Sen} 2 b$ null mice and their littermate controls

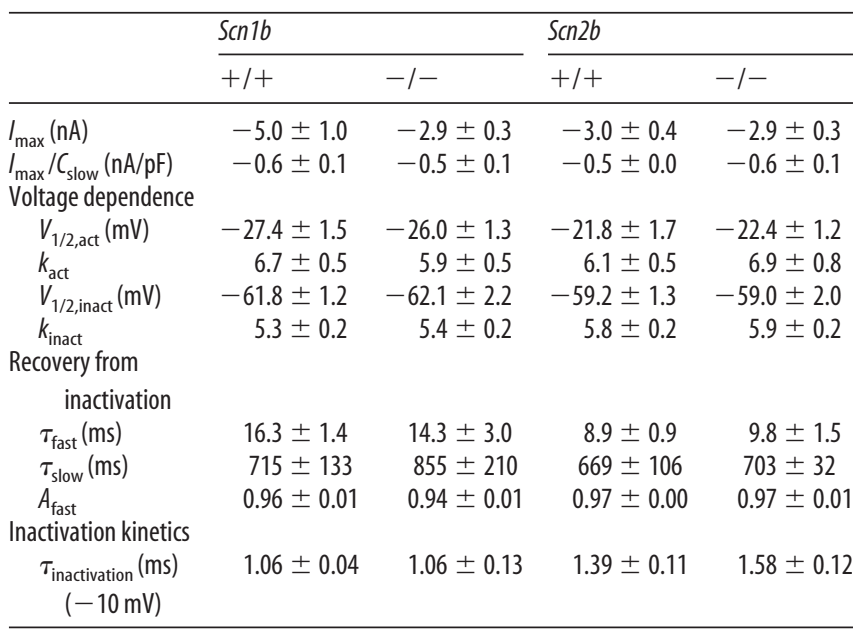

$\mathrm{mV}$ was measured between the intracellular and extracellular solutions for both pairs of solutions and corrected so that data points were shifted in a depolarizing direction relative to the voltage axis. We obtained tight-seal whole-cell recordings with an EPC9 amplifier (HEKA; seal resistance: $1 \mathrm{G} \Omega$, series resistance: $<9 \mathrm{M} \Omega$ ). Series resistance was compensated between $50 \%$ and $70 \%$. Experiments in which the maximal residual voltage error exceeded $2.5 \mathrm{mV}$ were rejected. Current signals were filtered at $10 \mathrm{kHz}$ ( $3 \mathrm{~dB}$, four-pole low-pass Bessel filter) and sampled at $20 \mathrm{kHz}$ or more by an interface (ITC16; Instrutech). For analysis of $I_{\mathrm{NaT}}$, we subtracted residual capacitance transients and leak conductance with a $\mathrm{P} / 4$ protocol and analyzed the $\mathrm{Na}^{+}$current properties as described previously (Schaub et al., 2007). No P/4 protocol was applied for recordings of $I_{\mathrm{NaP}}$. All voltage-clamp experiments were performed at room temperature $\left(22 \pm 1^{\circ} \mathrm{C}\right)$.

Sharp microelectrode recordings. For intracellular sharp microelectrode recordings, $400-\mu \mathrm{m}$-thick hippocampal slices were placed in an interface chamber $\left(35 \pm 1^{\circ} \mathrm{C}\right)$ and perfused with oxygenated ACSF containing the following (in mM): $125 \mathrm{NaCl}, 3.5 \mathrm{KCl}, 1.25 \mathrm{NaH}_{2} \mathrm{PO}_{4}, 2 \mathrm{MgSO}_{4}, 2 \mathrm{CaCl}_{2}$, $26 \mathrm{NaHCO}_{3}$, and $15 \mathrm{D}$-glucose. Intracellular recordings were obtained using sharp glass microelectrodes containing $4 \mathrm{M} \mathrm{K}^{+}$-acetate $(90-110 \mathrm{M})$. An active bridge circuit in the amplifier (Axoclamp 2B, Molecular Devices) allowed simultaneous injection of current and measurement of membrane potential. After stabilization of neurons, CBZ $(100 \mu \mathrm{M})$ was applied by adding it to the ACSF. The effects of CBZ saturated $15 \mathrm{~min}$ after washin and were quantitatively evaluated $20 \mathrm{~min}$ after washin. Bridge balance was carefully adjusted before each measurement and experiments were discarded when it changed by $>10 \%$. The signals were filtered on-line at $10 \mathrm{kHz}$, digitized at a sampling rate of $100 \mathrm{kHz}$ and stored on hard disk (pClamp 8, Molecular Devices).

Drugs. CBZ (RBI/Sigma) was dissolved in ethanol. Identical concentrations of ethanol were present in all control and CBZ-containing solutions. All other chemicals were obtained from Sigma.

Voltage-clamp paradigms and data analysis. The voltage dependence of activation and inactivation was determined using the protocol depicted in Figure $1 \mathrm{~A}$. Activation was assessed during an initial voltage jump to potentials between -100 and $+10 \mathrm{mV}(500 \mathrm{~ms}$ ) (for current traces, see Fig. $1 B$, left). Inactivation was probed by examining the currents elicited by a subsequent voltage step $(15 \mathrm{~ms}, 10 \mathrm{mV}$ ) (Fig. $1 A$; for current traces, see Fig. $1 B$, right). The conductance $G(V)$ was calculated according to $G(V)=I(V) /\left(V-V_{\mathrm{Na}}\right)$, where $V_{\mathrm{Na}}$ is the $\mathrm{Na}^{+}$reversal potential, $V$ is the command potential, and $I(V)$ is the peak current amplitude. $G(V)$ then was fitted for each family of traces obtained from individual cells with the following Boltzmann equation: $G(V)=A_{1}+\left[\left(A_{0}-A_{1}\right) /\left(1+e^{\left(V-V_{1 / 2}\right) / k}\right)\right]$, where $A_{0}$ and $A_{1}$ are $\mathrm{Na}^{+}$conductances, $V_{1 / 2}$ is the voltage where $G(V)$ is half of maximal conductance $\left(V_{1 / 2, \text { act }}\right.$ and $V_{1 / 2 \text {,inact }}$ are half-maximal activation and inactivation, respectively), and $k$ indicates the slope of the relation between channel activation or inactivation and membrane voltage.
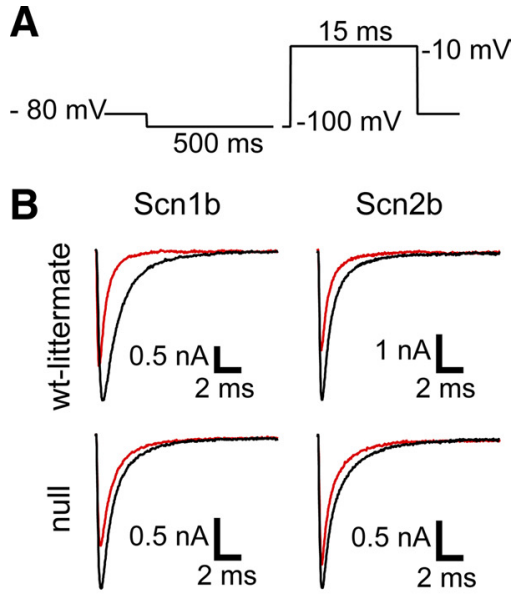

C

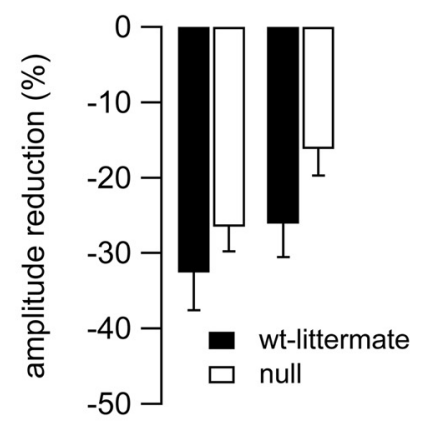

릉 टे

Figure 2. $\left(B Z\right.$ reduces $\mathrm{Na}^{+}$current amplitude, and this effect is unaltered in mice lacking either $\operatorname{Scn} 1 b$ or $S \mathrm{cn} 2 b$. A, A voltage step to $-10 \mathrm{mV}$ (15 ms) was applied to elicit maximal $\mathrm{Na}^{+}$currents. $\boldsymbol{B}$, Representative currents before (black) and during (red) application of $100 \mu \mathrm{m}$ CBZ are depicted for Scn $1 b$ wild-type and Scn2b wild-type (upper traces) and for $S \mathrm{c} n 1 b$ null and $S \mathrm{c} n 2 b$ null (lower traces). $C$, The fraction of channels blocked by CBZ was averaged for all cells. Neither loss of $\operatorname{Sen} 1 b[32.6 \pm 5.0 \%$ vs $26.5 \pm 3.3 \%$ for $+/+$ $(n=11)$ and $-/-(n=6)$ animals, respectively; n.s.] nor $\operatorname{Sen} 2 b[26.1 \pm 4.4 \%$ vs $16.2 \pm 3.5 \%$ for $+/+(n=5)$ and $-/-(n=7)$ animals, respectively; n.s.] causes a significant reduction of the blocking effect of CBZ.

Double pulse experiments to analyze recovery from inactivation were performed according to established protocols as depicted in Figure $1 D$. A conditioning pulse from -80 to $-10 \mathrm{mV}(15 \mathrm{~ms})$ was followed by a varying recovery period ( 1 to $8192 \mathrm{~ms}$ ) at $-80 \mathrm{mV}$ and a subsequent test pulse to $-10 \mathrm{mV}(15 \mathrm{~ms})$. Time constants of recovery $\tau_{\text {fast }}$ and $\tau_{\text {slow }}$ were extracted from the data points by fitting with a biexponential equation: $I(t)=A_{0}+A_{\text {fast }}\left(e^{-\Delta t / \tau_{\text {fast }}}\right)+A_{\text {slow }}\left(e^{-\Delta t / \tau_{\text {slow }}}\right)$, where $I(t)$ is the normalized peak current amplitude following a recovery period of the duration $\Delta t, A_{\text {fast }}$ and $A_{\text {slow }}$ are the relative amplitude contributions of the fast and slow recovery time constants $\tau_{\text {fast }}$ and $\tau_{\text {slow }}$, and $A_{0}$ is a constant offset. A nonlinear Levenberg-Marquardt algorithm was used for all fits. In all cases, fits were performed on the data points obtained from individual cells, and these parameters were then averaged. All results are presented as the mean \pm SEM.

Current-clamp data analysis. The voltage traces recorded in currentclamp mode with sharp microelectrodes were analyzed with Igor Pro 6.01 (Wavemetrics). We characterized action potential morphology using short current injections $(3 \mathrm{~ms})$. Action potentials were described quantitatively by determining their peak amplitude, the maximal rate of rise of the voltage trace, and the half-width measured at the voltage intermediate between action potential threshold and peak. The action potential threshold was determined as the voltage at which the slope of the voltage trace exceeded $15 \mathrm{mV} / \mathrm{ms}$ (Sekerli et al., 2004). Repetitive firing was examined using prolonged current injections (500 ms). Input- 
output relations were obtained with an automatic action potential detection routine programmed in Igor Pro 6.01. To assess the subthreshold excitation, we used defined current injections set to a value of $2 \times(S c n 1 b)$ or $1.5 \times(\operatorname{Scn} 2 b)$ the threshold current injection. We determined the slope of the interspike interval as the average of the first derivation of the voltage trace within the interspike interval from the most hyperpolarized point to the spike threshold. For this analysis, we chose the interspike interval preceding the first action potential detected beginning $100 \mathrm{~ms}$ after the start of the recording. This interspike interval was selected to ensure that passive charging of the membrane capacitance had completed for all cells to avoid contamination of the interspike slope.

Computational modeling studies. A model of a pyramidal neuron was adapted from Royeck et al. (2008) and contained biophysically realistic morphology (265 compartments) and 15 distributed voltage and/or $\mathrm{Ca}^{2+}$-dependent conductances (see supplemental Tables 1 and 2, available at www.jneurosci.org as supplemental material). Implementation was performed within the NEURON (Hines and Carnevale, 2001) modeling environment running on a dual core processor $(2.39 \mathrm{GHz}$ per core, 2 GB RAM) under Windows XP. Integration time steps were fixed at $0.025 \mathrm{~ms}$. Full details of the model are available at MODELDB (https://senselab.med.yale.edu/, click on ModelDB, executable model available under accession code 125152).

Briefly, $I_{\mathrm{NaP}}$ was implemented as an activating and non-inactivating $\mathrm{Na}^{+}$current as follows: $i_{\mathrm{NaP}}=\bar{g}_{\mathrm{NaP}} \cdot m \cdot\left(V-V_{\mathrm{Na}}\right)$, with $V$ and $V_{\mathrm{Na}}$ corresponding to the membrane potential and the $\mathrm{Na}^{+}$equilibrium potential, respectively, and $m$ describing the activation dynamics with the following equations:

$$
\begin{aligned}
m_{\infty} & =\frac{1}{1+\exp \left(-\left(V+52.3 \mathrm{mV}-\Delta V_{1 / 2}\right) / 6.8 \mathrm{mV}\right)} \\
\tau_{m} & =1 \mathrm{~ms},
\end{aligned}
$$

with $m_{\infty}$ and $\tau_{m}$ corresponding to the steadystate channel opening probability and the time constant of activation, respectively. The voltage dependence of activation was systematically varied in the model by altering the parameter $\Delta V_{1 / 2}$, which describes the shift in the voltage of half-maximal activation relative to a reference voltage of $-52.3 \mathrm{mV}$. The $I_{\mathrm{NaP}}$ conductance was present within the soma/ axon hillock and the axon initial segment, with $\bar{g}_{\mathrm{NaP}}$ at the soma/axon hillock being always $60 \%$ of $\bar{g}_{\mathrm{Nap}}$ at the axon initial segment. We varied these conductances systematically without altering the ratio. For simplicity, we give values for $\bar{g}_{\mathrm{NaP}}$ at the axon initial segment throughout the paper.

Statistical analyses. Statistical comparison was performed with a Student's $t$ test at a significance level $\alpha$ of 0.05 . Where appropriate, paired tests were used to compare the recordings before and during application of $100 \mu \mathrm{M}$ CBZ. Unpaired tests were used for group comparisons of null mice to their wild-type littermates regarding channel properties and CBZ effects. The results of the statistical analysis are given throughout the results and figure legends and significance levels $<0.05$ are indicated in the figures with asterisks.
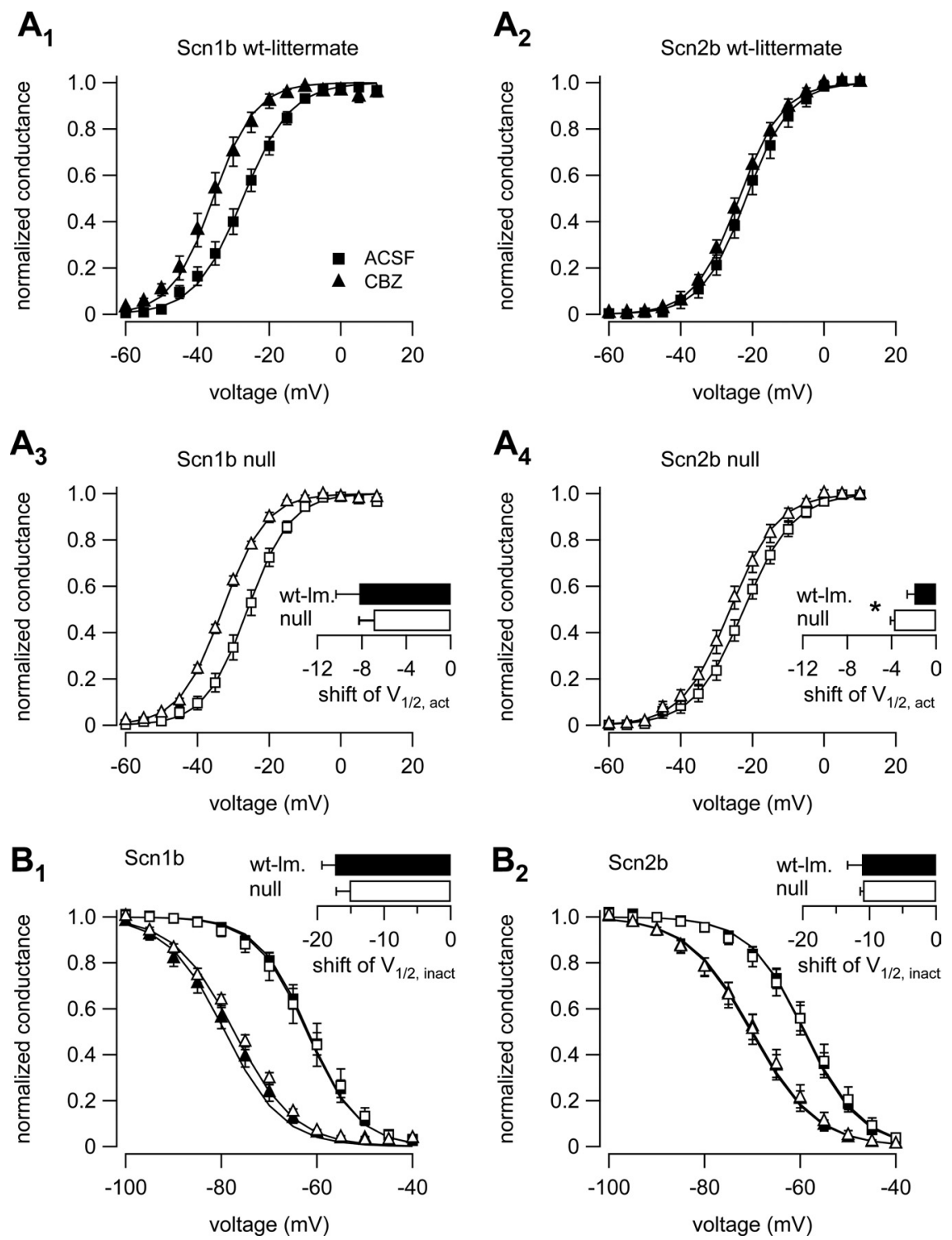

Figure 3. CBZ shifts the voltage dependence of activation to more hyperpolarized potentials, and this effect is enhanced in mice lacking $\operatorname{Scn} 2 b$. $A$, Voltage dependence of activation was analyzed according to Figure $1 A-C$ in the presence and absence of $C B Z$ (triangles and squares, respectively, in all panels). $A_{1}, A_{2}$, BZ induced a strong hyperpolarizing shift in the voltage dependence of activation in the younger $S \mathrm{cn} 1 b$ wild-type mice (P12-P20, shift in $V_{1 / 2, \text { act }}$ of $-8.2 \pm 2.1 \mathrm{mV}, n=11, A_{1}$ ), and a less pronounced, but still significant, effect in the adult $S \mathrm{C} n 2 b$ wild-type mice ( $P 40-P 60$, shift in $V_{1 / 2, \text { act }}$ of $-1.9 \pm 0.6 \mathrm{mV}, n=6, p<0.05, A_{2}$ ). $A_{3}, A_{4}$ Comparison of the genotypes revealed a significant enhancement of the CBZ-induced left shift in $S c n 2 b$ null compared to Scn2b wild-type mice (shift in $V_{1 / 2 \text {,act }}$ of $-3.8 \pm 0.3 \mathrm{mV}$ in Scn2b null mice, $n=7, p<0.05, A_{4}$ ). Such an enhancement was not observed for Scn $1 b$ null compared to Scn $1 b$ wild-type mice (shift in $V_{1 / 2, \text { act }}$ of $-6.9 \pm 1.3 \mathrm{mV}$ in $\operatorname{Scn} 1 b$ null, $n=5$, n.s., $A_{3}$, see insets in $\boldsymbol{A}_{3}$ and $\boldsymbol{A}_{4}$ ). $\boldsymbol{B}$, Analysis of the voltage dependence of inactivation (see Fig. $1 A-C$ for protocols and example traces) revealed a strong $\mathrm{CBZ}$-induced hyperpolarizing shift of the voltage dependence of inactivation independent of expression of $\mathrm{SCn} 1 b$ $\left(-17.4 \pm 2.0 \mathrm{mV}, n=11\right.$ and $-15.2 \pm 2.0 \mathrm{mV}, n=6$, for $+/+$ and $-/-$ animals, respectively, n.s., $\left.\boldsymbol{B}_{7}\right)$ and Scn $2 b$ $\left(-11.1 \pm 2.1 \mathrm{mV}, n=5\right.$ and $-11.0 \pm 0.4 \mathrm{mV}, n=7$, for $+/+$ and $-/-$ animals, respectively, n.s., $\boldsymbol{B}_{2}$, see insets for quantification; open symbols correspond to $S c n 1 b$ or $S c n 2 b$ null mice and filled symbols to their wild-type littermates).

\section{Results}

Properties of $I_{\mathrm{NaT}}$ in DG neurons are unaltered in mice lacking $\boldsymbol{\beta}_{1}$ or $\boldsymbol{\beta}_{2}$ subunits

We first examined whether the properties of transient $\mathrm{Na}^{+}$currents are altered in $\beta$ subunit null mice compared to littermate control mice. We examined the voltage dependence of $I_{\mathrm{NaT}}$ using a standard protocol (Fig. $1 \mathrm{~A}$ ). Voltage steps ranging from -100 to $+10 \mathrm{mV}$ (500 ms) were applied, followed by a constant voltage step to $-10 \mathrm{mV}$. The first of the two steps causes activation of $I_{\mathrm{NaT}}$, allowing analysis of the voltage dependence of activation 
$A_{1}$
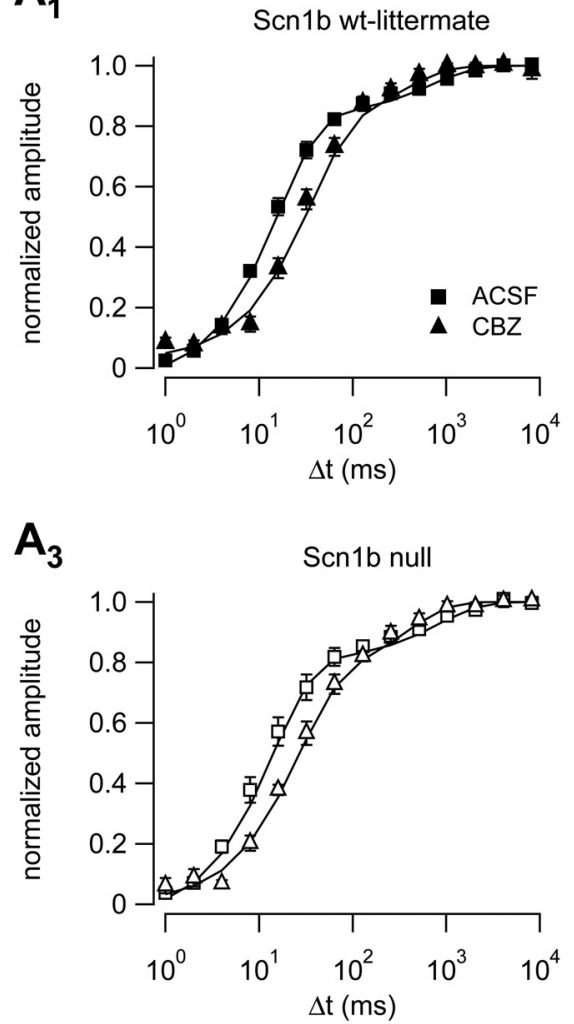

B

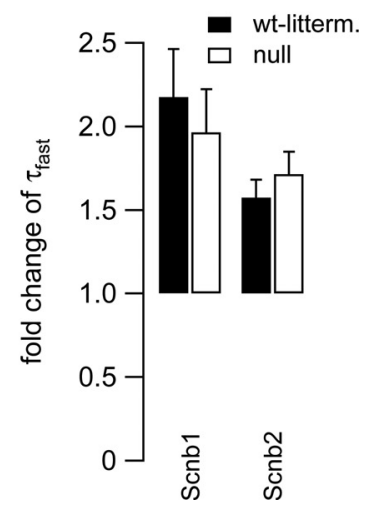

$\mathbf{A}_{2}$

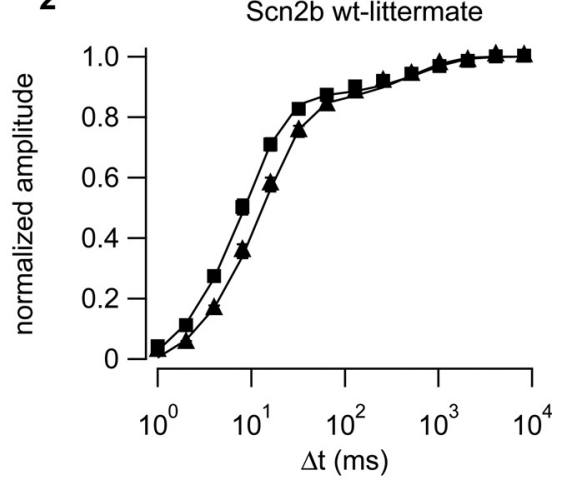

$\mathbf{A}_{4}$

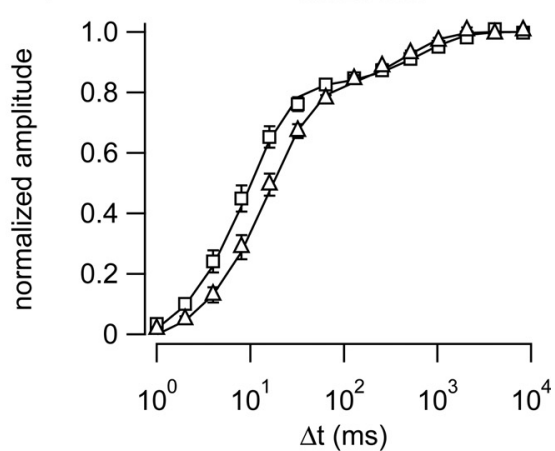

values for $V_{1 / 2}$ and the slope factor $k$ ). Likewise, neither the maximal amplitude of $I_{\mathrm{NaT}}$ elicited following full recovery of $\mathrm{Na}^{+}$currents from inactivation nor $I_{\mathrm{NaT}}$ current density was significantly altered (see Table 1). This finding is in contrast to previous studies showing consistently that $\operatorname{Scn} 2 b$ null neurons display reduced current density (Chen et al., 2002). However, we should note that our selection of cells with very low series resistance error (see Materials and Methods) introduces a considerable bias against including cells with large $I_{\mathrm{NaT}}$, and therefore also a bias against detecting differences in the magnitude of this current.

We also examined time-dependent inactivation and recovery from inactivation. The inactivation of $\mathrm{Na}^{+}$currents during voltage steps to $-10 \mathrm{mV}$ could be described by a monoexponential equation. The time-dependent inactivation was not different when comparing $\beta$ subunit null mice with the appropriate wild-type controls (see Table 1). The recovery from inactivation was analyzed by applying a voltage step to $-10 \mathrm{mV}(15 \mathrm{~ms})$. Subsequently, $\mathrm{Na}^{+}$current availability was recovered by repolarizing to $-80 \mathrm{mV}$ for variable time intervals (Fig. 1D) $(\Delta t$ : 1-8192 ms). Recovery of the $I_{\mathrm{NaT}}$ was assessed by a test pulse to $-10 \mathrm{mV}$ (Fig. $1 D$, representative current traces depicted in Fig. $1 E$ ). Recovery from inactivation was best fitted by a biexponential equation, as reported previously (Ellerkmann et al., 2001) (see Materials and Methods and superimposed line in Fig. $1 F$ ). We found no difference in the time constants and amplitude proportions describing the recovery from inactivation in $\beta$ subunit null mice compared to littermate control animals (Table 1).

CBZ effects on peak $I_{\mathrm{NaT}}$ amplitude are unaltered by deletion of $\beta$ subunits

We then asked whether the actions of CBZ on $\mathrm{Na}^{+}$channels are modified by loss of either $\beta_{1}$ or $\beta_{2}$ subunits. First, we determined whether the effects of CBZ (100 $\mu \mathrm{M})$ on the maximal current amplitude are altered. Maximal current amplitudes were obtained by stepping to $-100 \mathrm{mV}$

(Fig. $1 \mathrm{~B}$, left panel). The voltage dependence of inactivation was determined by measuring current amplitudes during the second, constant voltage step to $-10 \mathrm{mV}$ (Fig. $1 A, B$, rightmost panel). Peak amplitudes were converted to conductance, normalized, and plotted versus the voltage (Fig. $1 C$; black squares and circles correspond to activation and inactivation, respectively) and fitted with a Boltzmann equation superimposed on the data points (see Materials and Methods). This analysis revealed that genetic deletion of either $S c n 1 b$ or $S c n 2 b$ did not cause changes in the voltage dependence of activation or inactivation (see Table 1 for for $500 \mathrm{~ms}$ to induce recovery from fast inactivation and then eliciting $\mathrm{Na}^{+}$currents by stepping to $-10 \mathrm{mV}$ (Fig. 2A). CBZ reduced the amplitude of $I_{\mathrm{NaT}}$ in all genotypes (Fig. $2 B$; black traces correspond to control recordings; red traces were recorded during CBZ application). The magnitude of inhibition ranged from $\sim 15-35 \%$ and was not significantly different when comparing wild-type and mutant mice (Fig. 2C). We should note that the time course of the decay of the current was accelerated by CBZ. When this phenomenon was quantified at command potentials of $-10 \mathrm{mV}$, there was a significant reduction in $\tau_{\text {inact }}$ for 
all genotypes. This effect was seen over a large range of command potentials, and its magnitude was not significantly different in null animals compared to their wild-type littermates (supplemental Fig. 1, available at www.jneurosci.org as supplemental material; significant differences are indicated with asterisks).

\section{CBZ effects on the voltage dependence} of activation of $I_{\mathrm{NaT}}$ are enhanced in mice lacking $\boldsymbol{\beta}_{\mathbf{2}}$ subunits

The voltage dependence of activation was determined as described above (Fig. 1) in the absence and presence of CBZ. In both the $S c n 1 b$ littermate controls (P12-P20) and the older (P40-P60) Scn2b littermate control mice, CBZ caused a significant shift of the voltage dependence of activation toward more hyperpolarized potentials. This shift was significantly more pronounced in $S c n 1 b$ littermate control mice (Fig. $3 A_{1}, A_{2}$ ). This difference may reflect a developmental change in $\mathrm{Na}^{+}$ current pharmacology because $S c n 1 b$ mice were recorded at earlier developmental time points (P12-P20) than $S c n 2 b$ wild-type littermate control mice (P40P60, see Materials and Methods). Indeed when $\operatorname{Scn} 2 b$ littermate control mice were recorded at earlier time points (P12-P20), the shift of the voltage dependence of activation induced by CBZ was comparable to Scnlb littermate controls (shift of $V_{1 / 2 \text {,act }}=5.71 \pm 1.2 \mathrm{mV}, n=5$, n.s. compared to $S c n 1 b$ wild-type littermates). When we analyzed the effects of CBZ in $S c n 1 b$ null mice (Fig. $3 A_{3}$ ), we found no difference in the CBZ-induced shift of $V_{1 / 2 \text {,act }}$ compared to the wild-type animals (Fig. 3, compare $A_{1}$ and $A_{3}$, shift of $V_{1 / 2 \text {,act }}$; see inset in $A_{3}$ ). In contrast, loss of $S c n 2 b$ resulted in a significantly larger shift of the voltage dependence of activation following application of CBZ compared to wildtype littermates (Fig. 3, compare $A_{2}$ and $A_{4}$; see inset of $A_{4}$ for quantification). This finding indicates that the presence of $\beta_{2}$ subunits modulates the effects of CBZ on voltage-dependent activation of $I_{\mathrm{NaT}}$, although the extent of this modulation is very subtle (difference in CBZ-induced shift of $V_{1 / 2 \text {,act }}$ of only $\sim 2 \mathrm{mV}$ ) (Fig. $3 A_{4}$, inset).

In contrast, the classical effects of CBZ on voltage-dependent inactivation (analyzed as depicted in Fig. 1) were identical in $S c n 1 b$ null compared to wild-type littermate mice (Fig. $3 B_{1}$ ), as well as when we compared $S c n 2 b$ null to wild-type littermate mice (Fig. $3 B_{2}$, shift in $V_{1 / 2 \text {,inact }}$ depicted in the insets).

\section{CBZ effects on recovery from inactivation of $I_{\mathrm{NaT}}$ are unaltered by deletion of $\boldsymbol{\beta}$ subunits}

CBZ powerfully slows the time course of recovery from inactivation in dentate granule neurons. This effect is diminished or even abolished in most therapy refractory epilepsy patients and the respectively).

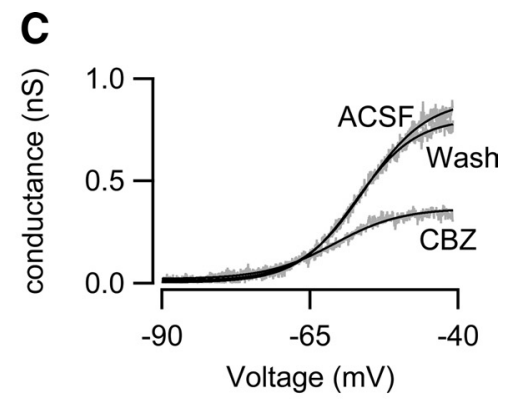

D

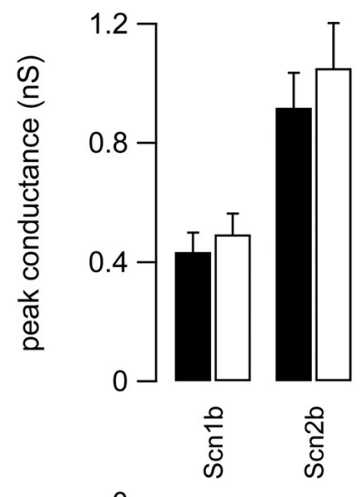

E

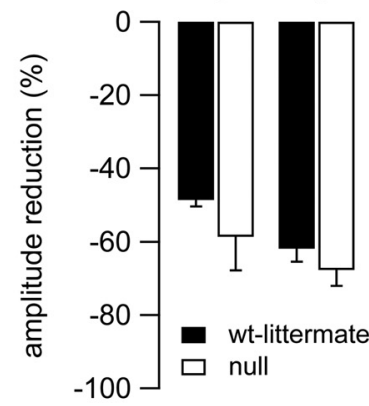

Figure 5. CBZ reduces the amplitude of $I_{\mathrm{NaP}}$ independent of the $\beta$ subunit expression. $\boldsymbol{A}, I_{\mathrm{NaP}}$ was elicited by a slow voltage ramp $50 \mathrm{mV} / \mathrm{s}$ ). $\boldsymbol{B}_{1}$, Representative current traces before (trace a), during (trace b), and after (trace c) washout of $100 \mu \mathrm{m}$ (BZ, and dence of activation was fitted with a Boltzmann equation (superimposed black lines). $\boldsymbol{D}$, Maximal conductances were

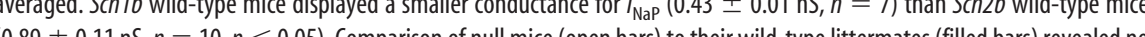
genotype-dependent difference in $/$ Nap amplitude $(0.49 \pm 0.07 \mathrm{nS}, n=6$ and $1.00 \pm 0.16 \mathrm{nS}, n=9$ for $S \mathrm{cn} 1 b$ null and $\operatorname{Scn} 2 b$ null mice, respectively). $\boldsymbol{E}$, The amplitude reduction following (BZapplication was similar [ $48.1 \pm 1.8 \%$ and $58.6 \pm 9.2 \%$ reduction for $S c n 1 b$ wild-type littermates and Scn1b null mice (n.s.) and $61.9 \pm 3.5 \%$ and $67.7 \pm 4.3 \%$ reduction for Scn2b wild-type littermates and Scn $2 b$ null mice (n.s.), respectively] in all experimental groups (filled and open bars for wild-type and null animals,

pilocarpine model of epilepsy (Remy et al., 2003; Schaub et al., 2007). This loss is in the latter model associated with a transient loss of mRNA encoding both $S c n 1 b$ and Scn $2 b$ (Ellerkmann et al., 2003). We therefore tested whether genetic deletion of either of these subunits in mice causes changes in the CBZ-induced slowing of the recovery from inactivation. The time course of recovery was analyzed as shown in Figure $1 D$. Application of CBZ caused pronounced slowing of the recovery from inactivation in both $S c n 1 b$ and $S c n 2 b$ control groups (Fig. $4 A_{1}, A_{2}$ ). Similar effects were observed for $S c n 1 b$ and $S c n 2 b$ null mice (Fig. $4 A_{3}, A_{4}$ ). When the time course of recovery from inactivation was described with a biexponential equation (see Materials and Methods), we did not find differences between $S c n 1 b$ null mice and wild-type littermates or between $S c n 2 b$ null mice and wild-type littermates regarding the CBZ-induced changes in time constants of recovery 
( $\tau_{\text {fast }}$ and $\tau_{\text {slow }}$ ) (Fig. $4 B, C$ ) or the corresponding amplitude contributions (Fig. 4D). One conclusion from this finding is that loss of one of the $\beta$ subunits alone is unlikely to account for loss of CBZ sensitivity of $\mathrm{Na}^{+}$channels, which has been previously described in chronic experimental epilepsy (Remy et al., 2003).

\section{$\mathrm{CBZ}$ effects on $I_{\mathrm{NaP}}$ in mice lacking $\boldsymbol{\beta}$ subunits}

After this analysis of $I_{\mathrm{NaT}}$, which showed a fast activation and inactivation, we examined CBZ effects on $I_{\mathrm{NaP}}$. This current corresponds to a small fraction of the cellular $\mathrm{Na}^{+}$current that does not inactivate during prolonged depolarization. $I_{\mathrm{NaP}}$ activates at more hyperpolarized potentials than $I_{\mathrm{NaT}}$ and thereby modulates the excitability of the membrane at subthreshold potentials. $I_{\mathrm{NaP}}$ was elicited with a slow voltage ramp (slope $50 \mathrm{mV} / \mathrm{s}$ ) (Fig. $5 \mathrm{~A}$ ) to prevent activation of $I_{\mathrm{NaT}}$. In the corresponding current traces, an inward current reflecting $I_{\mathrm{NaP}}$ could be observed in all cells (Fig. $5 B_{1}$, trace a), and this current was reversibly reduced in magnitude by the application of $100 \mu \mathrm{M} \mathrm{CBZ} \mathrm{(Fig.} 5 B_{1}$, traces b and c). To isolate $I_{\mathrm{NaP}}$ from other ionic currents that might contribute to the ramp-induced currents, we applied $0.5 \mu \mathrm{M}$ TTX at the end of all experiments. The trace recorded in the presence of TTX (Fig. $5 B_{1}$, trace d) was then subtracted from all other traces to obtain pharmacologically separated $I_{\mathrm{NaP}}$. The resulting current traces demonstrate a potent blocking effect of CBZ on the peak $I_{\mathrm{NaP}}$ (Fig. $5 B_{2}$ ). The current traces were corrected for the driving force (see Materials and Methods), the resulting conductance traces are depicted versus the ramp voltage in Figure $5 C$, and were fitted with a Boltzmann equation (see Materials and Methods, fits superimposed on conductance traces). The average peak conductance derived from Boltzmann fits was not significantly different when comparing $S c n 1 b$ or $S c n 2 b$ null mice to the appropriate littermate controls (Fig. 5D). We did note an increased magnitude of $I_{\mathrm{NaP}}$ when comparing the littermate controls for $\operatorname{Scn} 2 b$ to the littermate controls for $S c n 1 b$. As $S c n 2 b$ controls were older than the Scn $1 b$ controls (P40-P60 vs P12-P20), and the Scn $2 b$ wild-type littermates showed a similar small amplitude when recorded at the same age (P12-P20, $g_{\max }=0.46 \pm 0.18 \mathrm{nS}, n=5$, n.s. compared to $S c n 1 b$ wild-type littermates), this probably reflects a developmental increase in $I_{\mathrm{NaP}}$ (Fry, 2006). When we then considered the effects of $\mathrm{CBZ}$ on $I_{\mathrm{NaP}}$, we found similar blocking effects of CBZ, with $\sim 50 \%$ reduction of $I_{\mathrm{NaP}}$ following $\mathrm{CBZ}$ application in all experimental groups (Fig. $5 E$ ).

The analysis of $I_{\mathrm{NaT}}$ had revealed a slight shift of the voltage of half-maximal activation to more hyperpolarized potential following application of CBZ. We wondered whether a similar effect could be observed for $I_{\mathrm{NaP}}$. We determined the voltage dependence of activation by fitting $I_{\mathrm{NaP}}$ conductance-voltage relations as described in Figure $5 C$ in the absence and presence of CBZ. $I_{\mathrm{NaP}}$ conductance was normalized to the peak conductance of each trace to visualize the voltage dependence of activation before and during application of CBZ and after washout. In these recordings, a large hyperpolarizing shift of $I_{\mathrm{NaP}}$ voltage dependence of activation following CBZ application was apparent (Fig. 6A). This shift was reminiscent of the shift observed for $I_{\mathrm{NaT}}$ (Fig. $3 A$ ) but was more pronounced. A quantitative analysis of this phenomenon in the different genotypes is depicted in Figure 6, $B_{1}$ (Scn1b null and wild-type littermates) and $B_{2}$ (Scn2b null and wild-type littermates). For generation of the voltage relations shown in this figure, voltage traces obtained from individual cells were first fitted separately. The parameters obtained were averaged and then used to construct voltage relations representative of the different experimental groups. This analysis clearly shows a shift toward more hyperpolarized potentials induced by CBZ,
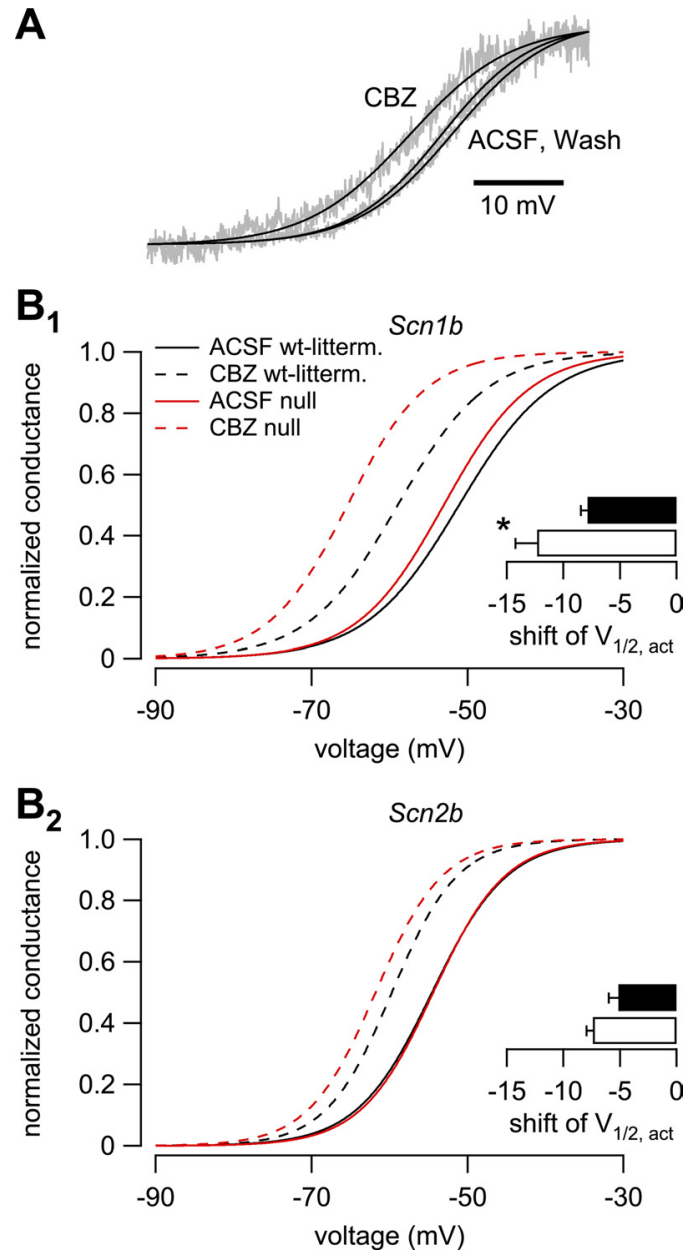

Figure 6. CBZ shifts the voltage dependence of $I_{\mathrm{NaP}}$ to more hyperpolarized potentials, and this effect is strongly augmented by genetic deletion of $\operatorname{Sen} 1 b$. $A$, To visualize the voltage dependence of activation, the conductance was normalized to the maximal conductance of $I_{\mathrm{NaP}}$ during the voltage ramp. This analysis reveals a pronounced left shift induced by CBZ. B, Activation curves calculated from the average fit parameters of all cells are depicted before (solid lines) and during (dashed lines) CBZ application for wild-type (black lines) and $\beta$ subunit null (red lines) mice. Deletion of $\operatorname{Scn} 1 b\left(\boldsymbol{B}_{1}\right)$ but not $\operatorname{Sen} 2 b\left(\boldsymbol{B}_{2}\right)$ resulted in an increased CBZ effect $[-12.3 \pm 1.9 \mathrm{mV}$ compared to $-7.9 \pm 0.6 \mathrm{mV}$ shift for $\operatorname{Sen} 1 b$ null $(n=6)$ and $\operatorname{Scn} 1 b$ wild-type $(n=7)$ mice $(p<0.05)$ and $-6.0 \pm 0.6 \mathrm{mV}$ compared to $-4.3 \pm 0.5 \mathrm{mV}$ shift for $S c n 2 b$ null $(n=9)$ and Scn2b wild-type $(n=10)$ mice (not significant), respectively] on the voltage dependence of activation (see insets).

which is significantly larger in $S c n 1 b$ null than in littermate wildtype mice (Fig. $6 B_{1}$; ACSF: full lines, CBZ: dashed lines, Scn $1 b$ littermate control and null mice, black and red lines, respectively). In contrast to these results for $S c n 1 b$, the CBZ-induced hyperpolarizing shift was not significantly different when comparing $S c n 2 b$ null to wild-type littermate mice (Fig. $6 B_{2}$, shift in $V_{1 / 2 \text {,act }}$ of $I_{\mathrm{NaP}}$ quantified in the insets of Fig. $\left.6 B_{1}, B_{2}\right)$.

The effect of CBZ on $I_{\mathrm{NaP}}$ was not fully reversible after washout in most cells. This could reflect incomplete washout of CBZ or a time-dependent change in the properties of $I_{\mathrm{NaP}}$. To assess the magnitude of the latter change, we recorded $I_{\mathrm{NaP}}$ without applying CBZ for a time period equivalent to the pharmacological experiments. We found a hyperpolarizing shift of $I_{\mathrm{NaP}}$ $(-3.1 \pm 1.2 \mathrm{mV}$ for Scn $1 b$ null mice, $n=3$, and $-5.1 \pm 0.4 \mathrm{mV}$ for $S c n 1 b$ littermate wild-type controls, $n=4$, n.s. when comparing genotypes). When we corrected the data presented in Figure $6 B_{1}$ for this shift, we find corrected shifts in $V_{1 / 2 \text {,act }}$ for $I_{\mathrm{NaP}}$ of -9.2 and $-2.8 \mathrm{mV}$ for $S c n 1 b$ null mice and littermate con- 
trols, respectively. Thus, time-dependent changes in $I_{\mathrm{NaP}}$ cannot account for the effects of Scn1b deletion on CBZ sensitivity of $I_{\mathrm{NaP}}$.

We then went on to examine whether the CBZ-induced hyperpolarizing shift in $I_{\mathrm{NaP}}$ activation indeed results in an increased inward current at membrane voltages close to the action potential threshold. To this end, we normalized the $I_{\mathrm{NaP}}$ conductance of each cell to the maximal conductance in the absence of CBZ and plotted the average normalized $I_{\mathrm{NaP}}$ conductance of $S c n 1 b$ null and littermate wild-type mice in the absence (Fig. $7 A_{1}$, continuous lines) and presence (Fig. $7 A_{1}$, dashed lines; $S c n 1 b$ null mice depicted in red) of CBZ. The curves obtained for $S c n 1 b$ null mice clearly show that $I_{\mathrm{NaP}}$ is increased substantially by CBZ application in the threshold range (approximately -80 to $-60 \mathrm{mV}$ ), while it is potently reduced at more depolarized potentials. The augmentation of $I_{\mathrm{NaP}}$ by CBZ is not apparent in $S c n 1 b$ littermate control mice. This finding became more apparent when the CBZ-induced increase in $I_{\mathrm{NaP}}$ conductance was quantified by subtraction (Fig. $7 B_{1}$; black lines and red lines correspond to $S c n 1 b$ null mice and their wild-type littermates, respectively). $I_{\mathrm{NaP}}$ proved to be approximately threefold increased following CBZ application in $S c n 1 b$ null mice, while this increase was much smaller in wild-type mice (Fig. $7 C_{1}$ ). In contrast to the results for $S c n 1 b$, a CBZ-induced increase in $I_{\mathrm{NaP}}$ conductance was not seen for $S c n 2 b$ null mice (Fig. $7 A_{2}-C_{2}$ ).

We then tested whether these paradoxical effects of CBZ are also observed at lower CBZ concentrations (10-100 $\mu \mathrm{M})$. These experiments revealed that the reduction of maximal $I_{\mathrm{NaP}}$ conductance increased dose dependently (Fig. 8A). Surprisingly, a significant hyperpolarizing shift in $V_{1 / 2 \text {,act }}$ was present already at the lowest concentration of $10 \mu \mathrm{M} \mathrm{CBZ} \mathrm{(Fig.} 8 B$ ). Concurrently, the concentration dependence of these two effects caused much larger paradoxical increase of $I_{\mathrm{NaP}}$ at low CBZ concentrations (Fig. 8C).

\section{CBZ effects on neuronal excitability in mice lacking $\boldsymbol{\beta}$ subunits}

We next examined whether the paradoxical, CBZ-induced upregulation of $I_{\mathrm{NaP}}$ in $S c n 1 b$ null mice has effects on neuronal excitability. We obtained sharp microelectrode recordings from CA1 pyramidal neurons of $S c n 1 b$ null and littermate wild-type mice (see Materials and Methods), and assessed their response to $100 \mu \mathrm{M}$ CBZ. The properties of single action potentials elicited by brief $(3 \mathrm{~ms})$ current injections showed only small differences between genotypes magnified range).
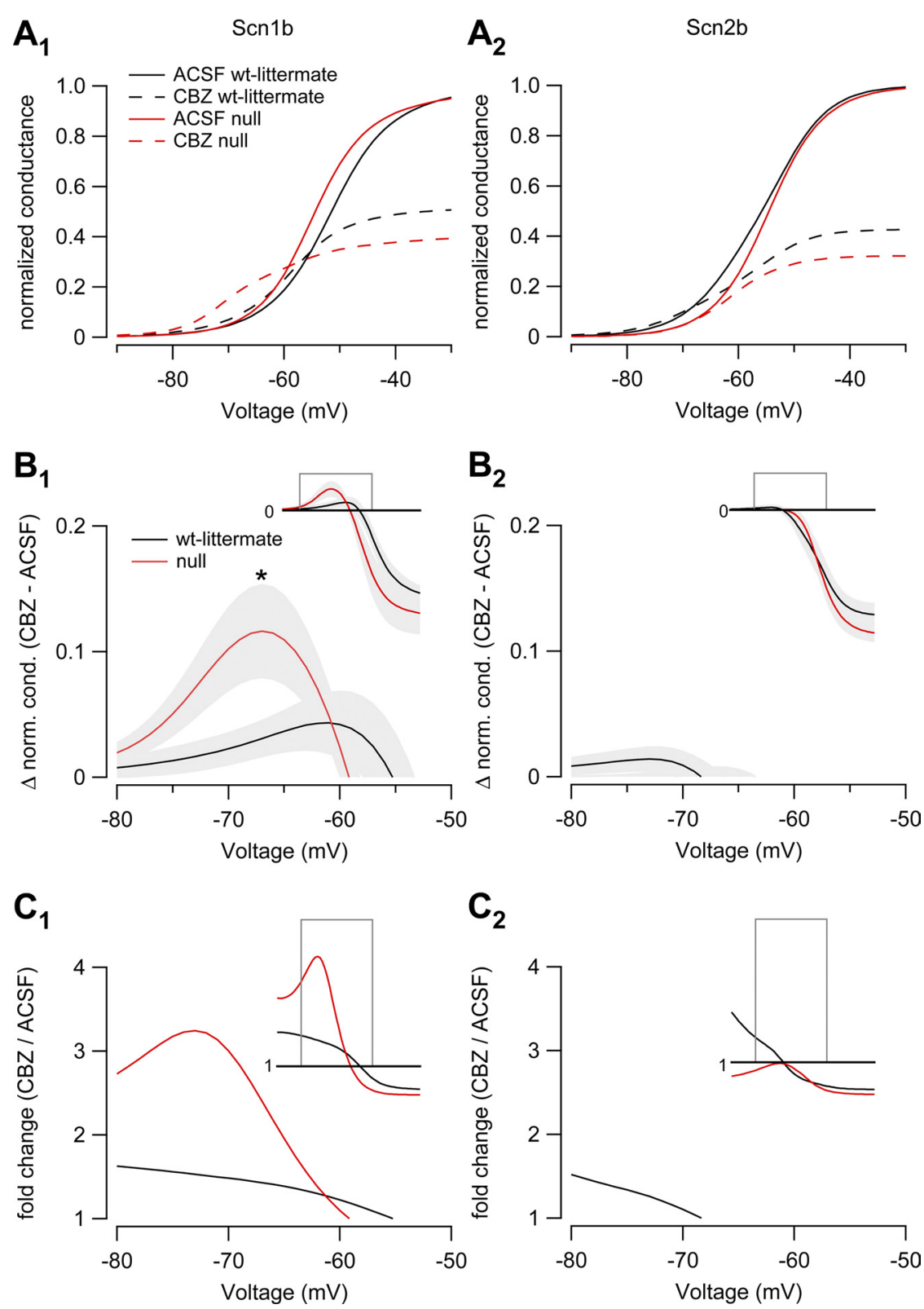

Figure 7. The hyperpolarizing shift of the voltage dependence of activation causes paradoxical effects of $\mathrm{CBZ}$ on $\mathrm{Nap}_{\mathrm{Na}}$ in $\mathrm{Scn} 1 \mathrm{~b}$ null mice. $A$, To demonstrate the net change in conductance resulting from the reduction in maximal amplitude (Fig. 5E) versus the shift in the voltage dependence (Fig. $\left.6 B_{1}, B_{2}\right), I_{\text {NaP }}$ conductance was normalized to the maximal conductance in the absence of (BZ. Activation curves calculated from the average fit parameters of all cells are depicted before (solid lines) and during (dashed lines) CBZ application for wild-type (black lines) and $\operatorname{Scn} 1 b\left(\boldsymbol{A}_{1}\right)$ or $\operatorname{Scn} 2 b\left(\boldsymbol{A}_{2}\right)$ null mice (red lines). This reveals an increase of conductance in the subthreshold range following application of $\mathrm{CBZ}$ in $\mathrm{S} \mathrm{C} 1 b$ null mice. $\boldsymbol{B}$, The difference in the normalized conductance before and during application of $C B Z$ was calculated to quantify the potentiating effects of $C B Z$ at subthreshold voltages. The increase of $I_{\text {NaP }}$ conductance induced by CBZ was significantly augmented $\left(\boldsymbol{B}_{1}, n=6, p<0.05\right.$ in the range -73 to $\left.-67 \mathrm{mV}\right)$ in the $S \mathrm{C} n 16$ null mice compared to wild-type mice $(n=7$, see inset for full range; gray area indicates \pm SEM for each data point; gray rectangle indicates the magnified range; note that the red trace does not lie within the magnified range and therefore is not depicted in $\boldsymbol{B}_{2}$ and $\boldsymbol{C}_{\mathbf{2}}$ but is present in the insets) but not in $\operatorname{Scn} 2 b$ null mice $(n=9)$ compared to their wild-type littermates $\left(n=10, \boldsymbol{B}_{2}\right)$. C, The (BZ-induced increase of $I_{\mathrm{NaP}}$ conductance was normalized to the conductance in the absence of CBZ. This reveals a more than threefold augmentation of $I_{\text {NaP }}$ conductance in the $S \mathrm{cn} 1 b$ null mice $\left(\boldsymbol{C}_{\mathbf{1}}\right.$; see inset for full range; gray rectangle indicates the

(with respect to action potential peak and half-width) (for data see supplemental Table 3, available at www.jneurosci.org as supplemental material). They were not altered by application of CBZ (data not shown). When repetitive firing was elicited by prolonged $(500 \mathrm{~ms})$ current injections, firing frequency was markedly reduced by $100 \mu \mathrm{M} \mathrm{CBZ}$ in both the Scn1b and the Scn $2 b$ 

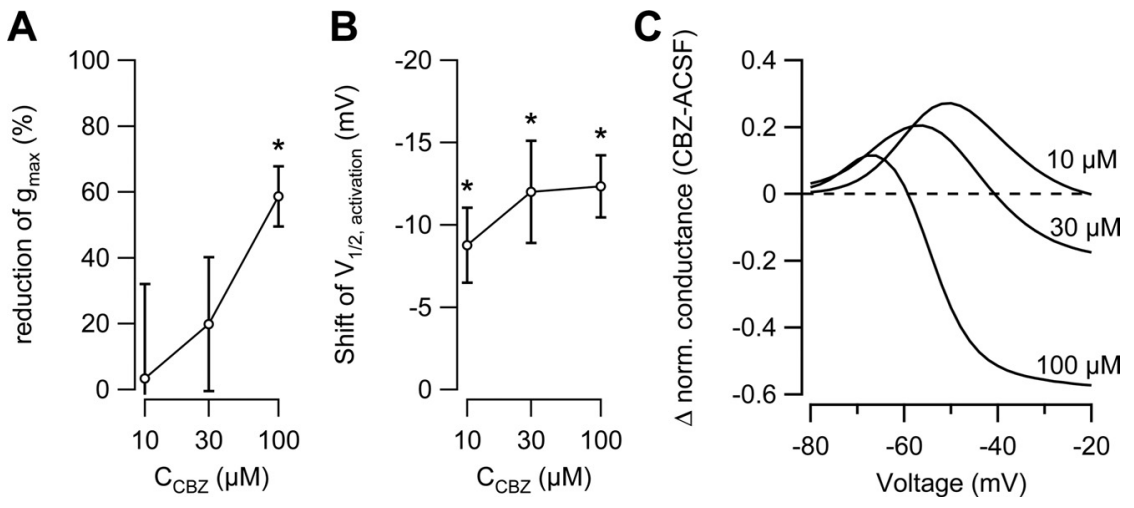

Figure 8. Concentration dependence of the paradoxical effect of $C B Z$ in $S c n 1 b$ null mice. Recordings identical to those described in Figure 5 were obtained before and during application of 10-100 $\mu \mathrm{M}$ CBZ. $A$, Reduction of the maximal $I_{\mathrm{NaP}}$ conductance following application of 10, 30, or $100 \mu \mathrm{M}$ CBZ. B , Shift of the voltage dependence of activation induced by $10-100 \mu \mathrm{m}$ CBZ.C, The CBZ effect expressed as fraction of the maximal conductance under control conditions (see Fig. 7) revealed larger paradoxical effects with lower concentrations of CBZ, compared to $100 \mu \mathrm{m} C B Z$.

littermate control mice, as expected (Fig. 9A, left, and Fig. $\left.9 B_{1}, B_{3}\right)$. In $S c n 1 b$ null mice, however, the firing frequency was not noticeably affected (Fig. $9 A$, right, and Fig. $9 B_{2}$ ). In contrast to $S c n 1 b$ null mice, $S c n 2 b$ null mice displayed a pronounced CBZ response (Fig. $9 B_{4}$ ) that seemed even larger than the $S c n 2 b$ littermate control mice (Fig. $9 B_{3}$ ). However, the magnitude of the CBZ effects was not different between $\operatorname{Scn} 2 b$ null and control mice.

To examine whether a hyperpolarizing shift of the $I_{\mathrm{NaP}}$ voltage dependence can counteract the effects of reducing $I_{\mathrm{NaP}}$ conductance, we systematically varied both parameters in a computational model (Fig. 10A; see Materials and Methods and link to ModelDB). To reduce the degrees of freedom in the parameters varied in these simulations, we confined ourselves to varying parameters of $I_{\mathrm{NaP}}$ only. We then induced firing in the model via current injections of increasing magnitude [from $0.4 \mathrm{nA}$ (lowermost traces) to $0.75 \mathrm{nA}$ (uppermost traces) for each modeling condition (Fig. 10A)]. The example traces already reveal that a reduction of $I_{\mathrm{NaP}}$ causes decreased firing. Conversely, a more hyperpolarized voltage dependence of $I_{\mathrm{NaP}}$ activation $\left(\Delta V_{1 / 2}=\right.$ $-8 \mathrm{mV}$ vs $-4 \mathrm{mV}$ ) causes markedly increased firing (Fig. $10 \mathrm{~A}$, compare left and right panels). This relationship is plotted over a range of current injections for the examples shown in Figure $10 \mathrm{~A}$ in Figure $10 B_{1}-B_{4}$ for different values of $\Delta V_{1 / 2}$ (indicated by grayscales in Fig. $10 B_{1}-B_{4}$ as indicated in $B_{4}$ ). The interrelation of $\Delta V_{1 / 2}$ and $I_{\mathrm{NaP}}$ conductance is plotted in Figure $10 C$ for an $800 \mathrm{pA}$ current injection step. This plot indicates that even large reductions of $I_{\mathrm{NaP}}$ at $\Delta V_{1 / 2}=0 \mathrm{mV}$ can be easily counteracted by simultaneous negative shifts in the voltage dependence of activation of $I_{\mathrm{NaP}}$ of the order of magnitude observed in $S c n 1 b$ null mice (approximately $-9 \mathrm{mV}$ ).

How can the CBZ-induced paradoxical increase in $I_{\mathrm{NaP}}$ in the subthreshold voltage range explain that CBZ fails to affect repetitive firing in $S c n 1 b$ null mice? We hypothesized that the increased magnitude of $I_{\mathrm{NaP}}$ in a subthreshold range might augment the rate at which the membrane potential re-depolarizes between individual spikes in a train, which would be expected to increase the spike rate. Indeed, an inspection of repetitive firing in $S c n 1 b$ null mice revealed that CBZ strongly augmented the rate of interspike depolarization (Fig. $11 A_{3}$, larger magnification in $A_{4}$; red traces correspond to traces obtained after CBZ application). In $S c n 1 b$ littermate control mice, no effects on the rate of interspike depolarization could be observed (Fig. 11 $A_{1}$, larger magnification in $A_{2}$, quantification shown in Fig. $11 B$, black bars). As expected, neither $S c n 2 b$ knock-out nor wild-type mice showed changes in the rate of interspike depolarization upon application of CBZ (Fig. $11 B$, white bars). These effects could be reproduced in the computational model. Systematically decreasing $I_{\mathrm{NaP}}$ conductance led to decreases in the interspike depolarization rate (Fig. $11 C_{1}-C_{3}$, compare light gray traces for $\Delta V_{1 / 2}=0 \mathrm{mV}$ ). Over the range of $I_{\mathrm{NaP}}$ conductances examined, hyperpolarizing shifts in $V_{1 / 2}$ led to opposing accelerations of interspike voltage (Fig. $11 C_{1}-C_{3}$, compare different $\Delta V_{1 / 2}$ values in each individual panel).

\section{Discussion}

The major result of our study is that the sensitivity of voltage-gated $\mathrm{Na}^{+}$channels to the anticonvulsant CBZ is strongly dependent on the presence of $\beta_{1}$ subunits within the channel complex. The most striking finding was that CBZ shifts the voltage dependence of activation of $I_{\mathrm{NaP}}$ toward more hyperpolarized potentials. Genetic deletion of $\beta_{1}$ significantly augments this leftward shift without altering other effects of CBZ. This novel effect is particularly intriguing because it increases $I_{\mathrm{NaP}}$ in the subthreshold voltage range, leading to a complete loss of CBZ efficacy in blocking repetitive firing. Thus, the presence of $\beta_{1}$ subunits within the channel complex appears to be crucial in determining the effects of CBZ on cellular excitability. This finding may be relevant in neurological disorders exhibiting a loss of $\beta$ subunit function.

\section{Effects of CBZ on $I_{\mathrm{NaT}}$ and $I_{\mathrm{NaP}}$}

We found that deletion of either $S c n 1 b$ or $S c n 2 b$ did not affect classical CBZ effects on $I_{\mathrm{NaT}}$ (Ragsdale and Avoli, 1998), i.e., reduction of the maximal amplitude, slowing of recovery from inactivation, and a hyperpolarizing shift in the voltage dependence of inactivation. $S c n 1 b$ or $S c n 2 b$ downregulation is thus unlikely to underlie changes in use-dependent block of $I_{\mathrm{NaT}}$ by CBZ observed in animal models of temporal lobe epilepsy (Ellerkmann et al., 2003; Remy et al., 2003; Schaub et al., 2007). The only effect observed on $I_{\mathrm{NaT}}$ was that $S c n 2 b$ but not $S c n 1 b$ deletion slightly but significantly increased the CBZ-induced hyperpolarizing shift in the activation curve. The CBZ-induced hyperpolarizing shift of the voltage dependence of activation of $I_{\mathrm{NaT}}$ was large in young control mice aged P12-P20 (littermates for Scn1b or Scn2b null mice, $\sim-7 \mathrm{mV}$ ), whereas it was much smaller in older (P40P60) Scn $2 b$ control mice. The age dependence of this effect may explain why it was so far not observed in older rats (Ragsdale and Avoli, 1998; Remy et al., 2003; Schaub et al., 2007).

Very similar effects were seen for $I_{\mathrm{NaP}}$, in which $\mathrm{CBZ}$ also shifted the activation curve toward more hyperpolarized potentials. In this case, the effects of deleting the $\beta_{1}$ subunits were large: the CBZ-induced hyperpolarizing shift in the activation curve was nearly doubled in the absence of $S c n 1 b$ but not altered in $S c n 2 b$ null mice. Interestingly, the blocking effects of CBZ on the peak amplitude of $I_{\mathrm{NaP}}$ were not modified in $S c n 1 b$ or $S c n 2 b$ null mice. Thus, the presence of $\beta_{1}$ subunits appears to selectively modify the effects of CBZ on the voltage dependence of $I_{\mathrm{NaP}}$. As a consequence, CBZ application in $S c n 1 b$ null mice resulted in a 
block of $I_{\mathrm{NaP}}$ at depolarized potentials, but increased $I_{\mathrm{NaP}}$ considerably at subthreshold voltages.

\section{Functional consequences of $\mathrm{CBZ}$ effects} on $I_{\mathrm{NaP}}$

Our combined modeling and physiological data indicate that the hyperpolarizing shifts in $I_{\mathrm{NaP}}$ voltage dependence counteract other effects of CBZ, both on $I_{\mathrm{NaP}}$ maximal conductance (Figs. 5-8) and on $I_{\mathrm{NaT}}$ (Figs. 2-4), most probably via an augmentation of the rate of interspike depolarization. The paradoxical increase of $I_{\mathrm{NaP}}$ in a confined subthreshold voltage range by CBZ may also be relevant for other aspects of subthreshold excitability of hippocampal pyramidal neurons, such as subthreshold resonance (Hu et al., 2002) and spike timing precision (Vervaeke et al., 2006).

The potential implications of this effect are intriguing. CBZ is used in the clinical treatment of many neurological diseases, like bipolar depression, multiple sclerosis, schizophrenia, myotonia, and dystonia, in addition to neuropathic pain and epilepsy (summarized in Rogawski and Löscher, 2004). Interestingly, $\beta$ subunits are shown to be differentially regulated in animal models of neurological disorders. In experimental autoimmune encephalomyelitis, a model of multiple sclerosis, both $S c n 1 b$ and $S c n 2 b$ are transcriptionally downregulated (Nicot et al., 2003). Likewise, in some types of neurons, denervation appears to result in reduced expression of $\beta_{1}$ subunits (Sashihara et al., 1996). Finally, in models of chronic temporal lobe epilepsy, both $S c n 1 b$ and $S c n 2 b$ mRNAs are downregulated (Gastaldi et al., 1998; Ellerkmann et al., 2003). In addition, a recent paper has shown that a functional null $S c n 1 b$ mutation can result in a severe form of childhood epilepsy (Dravet syndrome) (Patino et al., 2009). These studies suggest that downregulation of $\beta$ subunits is a pathological or adaptive response occurring in some common neurological diseases, and that this may affect the response to $\mathrm{CBZ}$ in these disorders.

\section{Effect of $\boldsymbol{\beta}$ subunit deletion on}

properties of $I_{\mathrm{NaT}}$ and $I_{\mathrm{NaP}}$

Our data also allow us to address the effects of deleting either $\beta_{1}$ or $\beta_{2}$ subunits on the biophysical properties of $I_{\mathrm{NaT}}$ and $I_{\mathrm{NaP}}$. We found that neither the amplitude nor the voltage dependence of $I_{\mathrm{NaP}}$ was altered in mice lacking $S c n 1 b$ or $S c n 2 b$, consistent with the data obtained in expression systems where only coexpression of $\beta_{3}$ subunits $(S c n 3 b)$ increased the amplitude of $I_{\mathrm{NaP}}(\mathrm{Qu}$ et al., 2001). Regarding the properties of $I_{\mathrm{NaT}}$, previous analyses of

A completely abolished.
Scn1b wt-littermate

Scn1b null
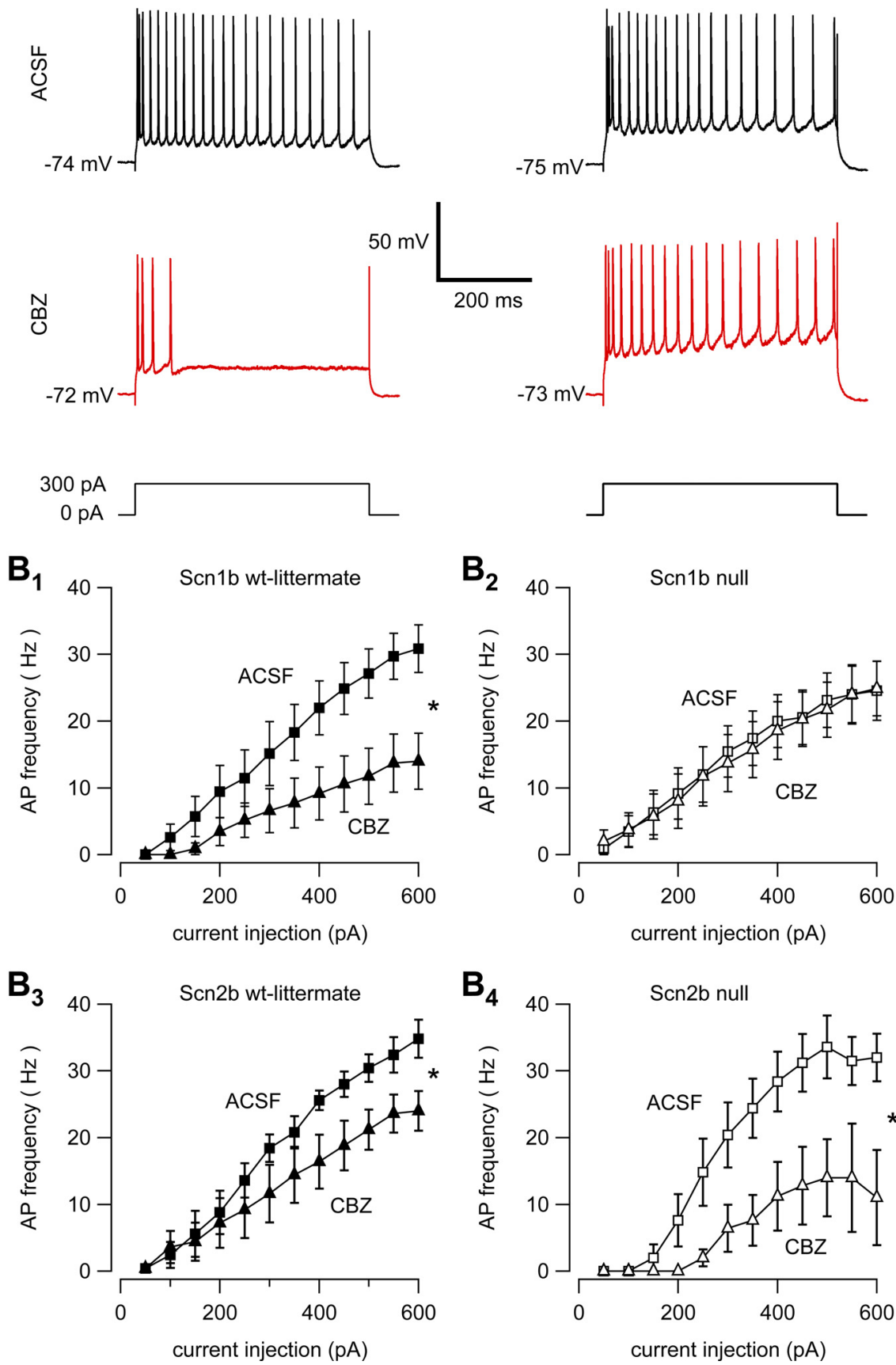

Figure 9. Paradoxical (BZ-induced upregulation of $/_{\mathrm{NaP}}$ and effects on neuronal excitability. $\boldsymbol{A}$, Current-clamp recordings from CA1 pyramidal neurons of $S \mathrm{Cn} 1 b$ null (right panels) and littermate wild-type mice (left panels). Repetitive firing was elicited by prolonged $(500 \mathrm{~ms}$ ) current injections as indicated in ACSF (black voltage traces) and following washin of 100 $\mu_{\mathrm{M}} \mathrm{CBZ}$ (red voltage traces). $\boldsymbol{B}$, Spike gain, depicted by plotting the mean firing rates versus the magnitude of the current injection steps. Analyses are shown for $\operatorname{Sen} 1 b$ null mice $\left(n=7, \boldsymbol{B}_{2}\right)$ and their littermate controls $\left(n=7, \boldsymbol{B}_{1}\right)$, as well as for Scn $2 b$ null mice $\left(n=5, B_{4}\right)$ and littermate controls $\left(n=5, B_{3}\right)$. The gain in the presence of CBZ (triangles) is compared to the gain in ACSF (squares) in all panels, revealing a significant reduction of the gain following application of CBZ in all experimental groups ( $p<0.05$, indicated by asterisks) except for the $S c n 1 b$ null mice, where the effect of $C B Z$ was

Scn $2 b$ null mice (Chen et al., 2002; Lopez-Santiago et al., 2006) or $S c n 1 b / 2 b$ null mice (Grieco et al., 2005) described reduced $I_{\mathrm{NaT}}$ current densities in both central and peripheral neurons, most probably due to a reduced insertion of channels into the plasma membrane. In addition, a small, but measurable, hyperpolarizing shift of the voltage dependence of inactivation 

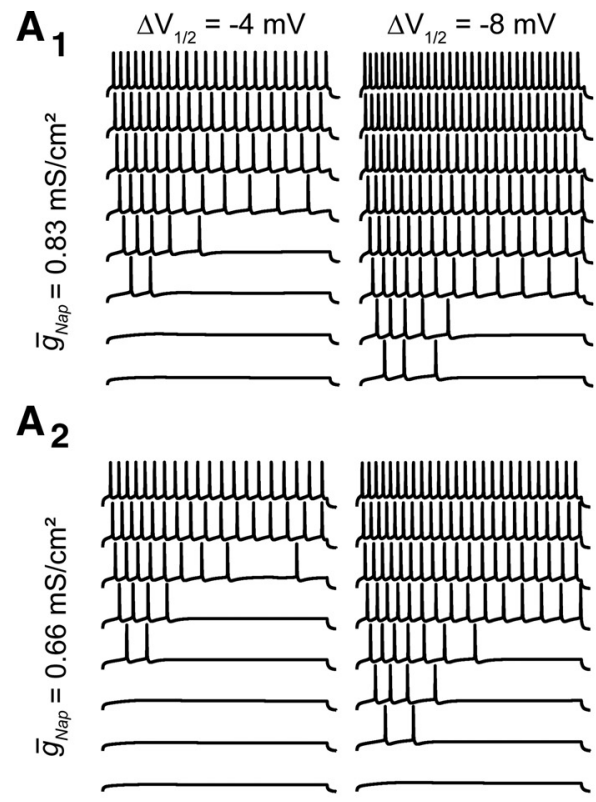

$\mathrm{A}_{3}$

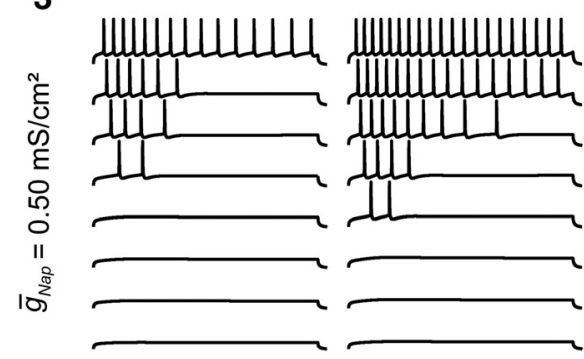

$\mathrm{A}_{4}$
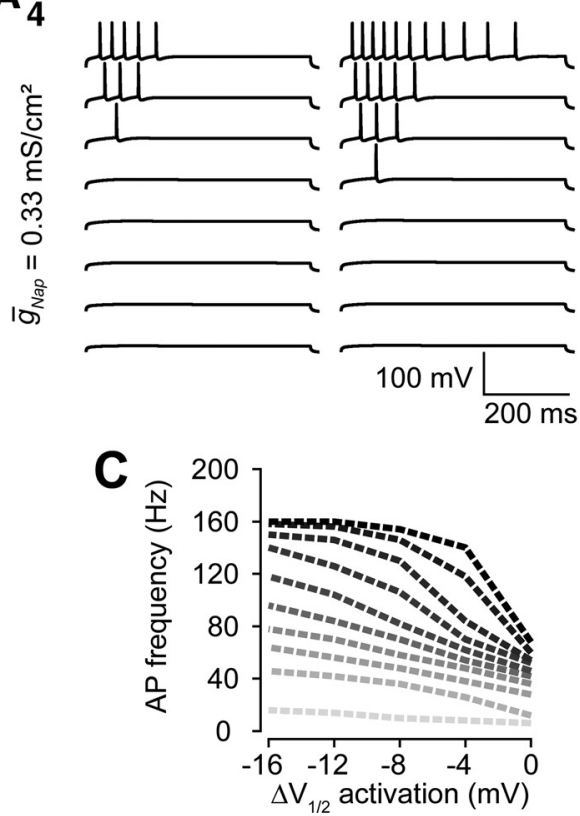

B

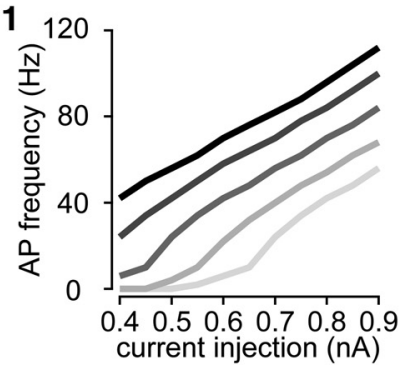

$\mathrm{B}_{2}$

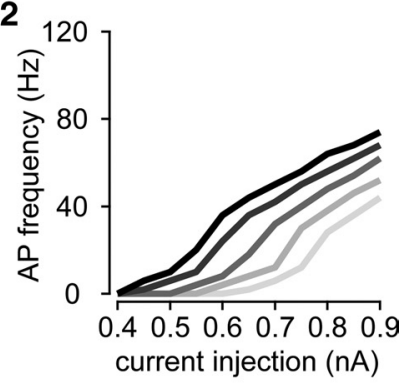

$\mathrm{B}_{3}$

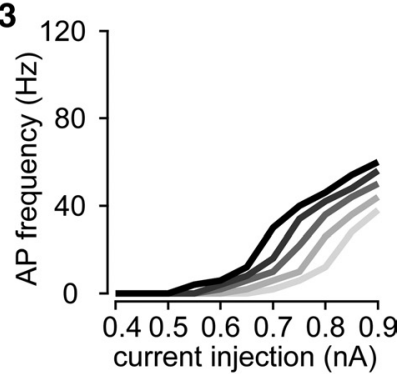

$\mathrm{B}_{4}$

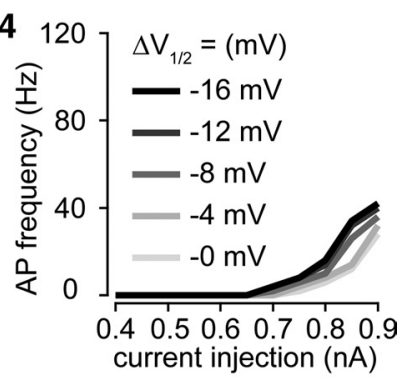

$\bar{g}_{\text {Nap }}=\left(\mathrm{mS} / \mathrm{cm}^{2}\right)$

$=0.16 \quad-=1.00$

$==0.33 \quad-=1.16$

$=0.50 \quad-\quad 1.33$

$= \pm=0.66 \quad-=-1.50$

=-- $0.83 \quad-\quad 1.66$

Figure 10. Computational model - effects of varying maximal $I_{\text {NaP }}$ conductance and voltage of half-maximal activation. $\boldsymbol{A}$, Examples of somatic current injections of increasing amplitude $(500 \mathrm{~ms}$ steps of 0.4 to $0.75 \mathrm{nA}$ from lowermost to uppermost traces in all panels) for different maximal $I_{\mathrm{NaP}}$ conductances $\left(A_{1}-A_{4}\right)$ and voltages of half-maximal activation of $I_{\mathrm{NaP}}\left(\Delta V_{1 / 2}\right.$ indicating relative shift of the $V_{1 / 2}$ of activation vs a value of $-52.3 \mathrm{mV}$ ). $B$, Gain plots of action potential frequencies versus the magnitude of the current injection step for the four different $I_{\text {NaP }}$ maximal conductances $\left(\boldsymbol{B}_{1}-\boldsymbol{B}_{4}\right)$ depicted in $\boldsymbol{A}$. Darker grayscales indicate larger $\Delta V_{1 / 2}$, i.e., more hyperpolarized $I_{\mathrm{NaP}}$ voltage dependence of activation (see inset in $\boldsymbol{B}_{4}$ ). $\boldsymbol{C}$, Interrelation of $\Delta V_{1 / 2}$ and $I_{\mathrm{NaP}}$ conductance for an $800 \mathrm{pA}$ current injection step for a larger range of values. Different maximal $I_{\mathrm{NaP}}$ conductances are indicated as hatched lines with different grayscales as indicated in the legend.

was observed in $S c n 2 b$ null hippocampal pyramidal (Chen et al., 2002), while the kinetics of tetrodotoxin-sensitive current activation and inactivation were slowed in Scn $2 b$ null DRG nociceptors with no measurable effects on voltage dependence (Lopez-Santiago et al., 2006). Deletion of $S c n 1 b$ did not alter the voltage dependence of activation or inactivation in hippocampal pyramidal neurons (Chen et al., 2004) or cerebellar granule cells (Brackenbury et al., 2010). In our experiments, we found no changes in biophysical properties of $I_{\mathrm{NaT}}$ in mice lacking either $\beta_{1}$ or $\beta_{2}$ subunits. The lack of difference in current density may be due to our strict selection criteria with regard to series resistance error, leading to rejection of cells with large currents (see Materials and Methods for exact criteria). The lack of difference in voltage dependence between $S c n 2 b$ null and wildtype mice in our study may be explained by the fact that Chen et al. (2002) used F1 hybrids, and mice congenic on $C 57 B L / 6$ were used in the present study. It should also be noted that $\beta$ subunit effects are apparently strongly modulated by as yet unknown, tissue-specific factors. This is suggested by studies describing very varied effects of $\beta$ subunit coexpression, depending on the expression system used for the study. For instance, coexpression of $\beta_{2}$ with $\mathrm{Na}_{\mathrm{v}} 1.2$ subunits in oocytes results in a small but significant negative shift in the voltage dependence of inactivation, with no change in voltage dependence of activation (Isom et al., 1995). In contrast in HEK293 cells, coexpression of either $\beta_{1}, \beta_{2}$, or $\beta_{3}$ with $\mathrm{Na}_{\mathrm{v}} 1.2$ subunits caused a shift of the voltage dependence of activation and inactivation toward more depolarized potentials when one of the three $\beta$ subunits was expressed, whereas the recovery behavior was not affected (Qu et al., 2001; Xu et al., 2007). This diversity underscores that the effects of $\beta$ subunit coexpression are likely modified by multiple signaling pathways and may explain why genetic deletion of $\beta$ subunits has cell-type-specific results (Meadows and Isom, 2005).

In conclusion, our study describes a paradoxical effect of CBZ on $I_{\mathrm{NaP}}$ in $S c n 1 b$ null mice caused by a CBZ-induced hyperpolarizing shift in voltage-dependent activation that results in a potent CBZinduced increase in $I_{\mathrm{NaP}}$ at subthreshold voltages. As a consequence, the inhibitory effects of CBZ on repetitive neuronal firing are largely lost. These results suggest that the presence of $\mathrm{Na}^{+}$channel $\beta_{1}$ sub- 
units may profoundly affect the response to anticonvulsant drugs in models of neurological disorders.

\section{References}

Brackenbury WJ, Isom LL (2008) Voltage-gated $\mathrm{Na}^{+}$channels: potential for beta subunits as therapeutic targets. Expert Opin Ther Targets 12:1191-1203.

Brackenbury WJ, Calhoun JD, Chen C, Miyazaki H, Nukina N, Oyama F, Ranscht B, Isom LL (2010) Functional reciprocity between $\mathrm{Na}^{+}$ channel Navl.6 and betal subunits in the coordinated regulation of excitability and neurite outgrowth. Proc Natl Acad Sci U S A 107:2283-2288.

Catterall WA (1999) Molecular properties of brain sodium channels: an important target for anticonvulsant drugs. Adv Neurol 79: 441-456.

Chen C, Bharucha V, Chen Y, Westenbroek RE, Brown A, Malhotra JD, Jones D, Avery C, Gillespie PJ 3rd, Kazen-Gillespie KA, Kazarinova-Noyes K, Shrager P, Saunders TL, Macdonald RL, Ransom BR, Scheuer T, Catterall WA, Isom LL (2002) Reduced sodium channel density, altered voltage dependence of inactivation, and increased susceptibility to seizures in mice lacking sodium channel beta 2-subunits. Proc Natl Acad Sci U S A 99: 17072-17077.

Chen C, Westenbroek RE, Xu X, Edwards CA, Sorenson DR, Chen Y, McEwen DP, O'Malley HA, Bharucha V, Meadows LS, Knudsen GA, Vilaythong A, Noebels JL, Saunders TL, Scheuer T, Shrager P, Catterall WA, Isom LL (2004) Mice lacking sodium channel $\beta 1$ subunits display defects in neuronal excitability, sodium channel expression, and nodal architecture. J Neurosci 24:4030-4042.

Ellerkmann RK, Riazanski V, Elger CE, Urban BW, Beck H (2001) Slow recovery from inactivation regulates the availability of voltagedependent $\mathrm{Na}^{+}$channels in hippocampal granule cells, hilar neurons and basket cells. J Physiol 532:385-397.

Ellerkmann RK, Remy S, Chen J, Sochivko D, Elger CE, Urban BW, Becker A, Beck H (2003) Molecular and functional changes in voltage-dependent $\mathrm{Na}^{+}$channels following pilocarpine-induced status epilepticus in rat dentate granule cells. Neuroscience 119:323-333.

Fry M (2006) Developmental expression of $\mathrm{Na}^{+}$currents in mouse Purkinje neurons. Eur J Neurosci 24:2557-2566.

Gastaldi M, Robaglia-Schlupp A, Massacrier A, Planells R, Cau P (1998) mrna coding for voltage-gated sodium channel beta2 subunit in rat central nervous system: cellular distribution and changes following kainateinduced seizures. Neurosci Lett 249:53-56.

Grieco TM, Malhotra JD, Chen C, Isom LL, Raman IM (2005) Openchannel block by the cytoplasmic tail of sodium channel beta 4 as a mechanism for resurgent sodium current. Neuron 45:233-244.

Hines ML, Carnevale NT (2001) Neuron: a tool for neuroscientists. Neuroscientist 7:123-135.

Hu H, Vervaeke K, Storm JF (2002) Two forms of electrical resonance at theta frequencies, generated by $\mathrm{m}$-current, $\mathrm{h}$-current and persistent $\mathrm{Na}^{+}$ current in rat hippocampal pyramidal cells. J Physiol 545:783-805.

Isom LL (2001) Sodium channel beta subunits: anything but auxiliary. Neuroscientist 7:42-54.

Isom LL, Scheuer T, Brownstein AB, Ragsdale DS, Murphy BJ, Catterall WA (1995) Functional co-expression of the beta 1 and type IIa alpha subunits of sodium channels in a mammalian cell line. J Biol Chem 270:3306-3312.

Lopez-Santiago LF, Pertin M, Morisod X, Chen C, Hong S, Wiley J, Decosterd I, Isom LL (2006) Sodium channel $\beta 2$ subunits regulate tetrodotoxintrace during the interspike interval.
$A_{2}$
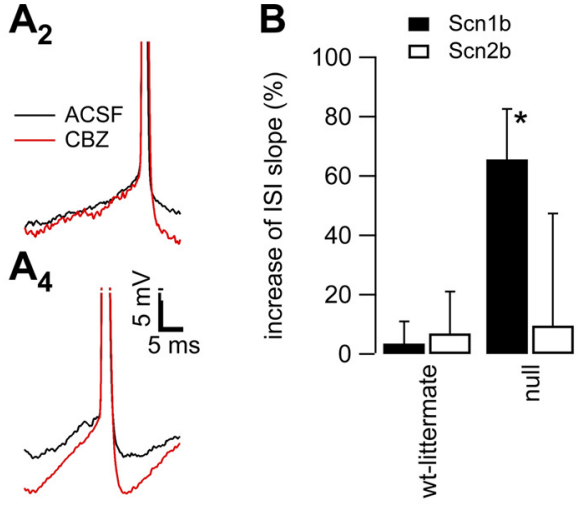

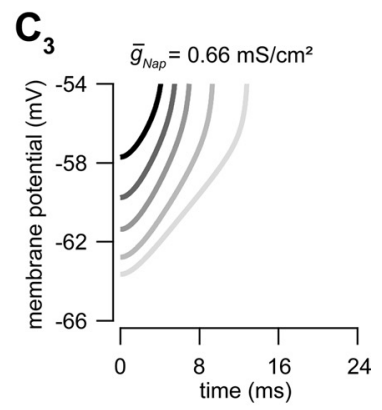

$\mathrm{C}_{2}$

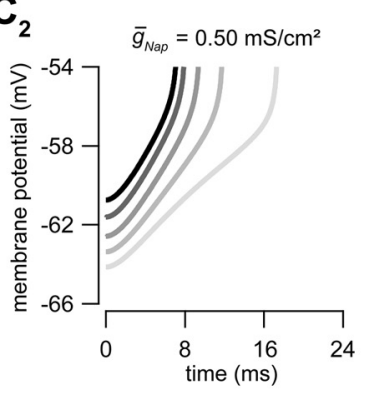

Figure 11. Effects of $C B Z$ in the subthreshold voltage range during repetitive firing. $A$, Black traces were obtained in traces were obtained following washin of CBZ. CBZ augments the rate of interspike depolarization in $\mathrm{Scn} 1 \mathrm{~b}$ Methods). The relative changes of the slope following application of $100 \mu \mathrm{m} \mathrm{CBZ} \mathrm{compared} \mathrm{to} \mathrm{the} \mathrm{slope}$ mal $I_{\mathrm{NaP}}$ conductances $\left(\boldsymbol{C}_{1}-\boldsymbol{C}_{3}\right)$. Zero point of the time axis in $\boldsymbol{C}$ is defined as the most hyperpolarized point of the voltage

sensitive sodium channels in small dorsal root ganglion neurons and modulate the response to pain. J Neurosci 26:7984-7994.

Lucas PT, Meadows LS, Nicholls J, Ragsdale DS (2005) An epilepsy mutation in the betal subunit of the voltage-gated sodium channel results in reduced channel sensitivity to phenytoin. Epilepsy Res 64:77-84.

Meadows LS, Isom LL (2005) Sodium channels as macromolecular complexes: implications for inherited arrhythmia syndromes. Cardiovasc Res 67:448-458.

Meadows LS, Chen YH, Powell AJ, Clare JJ, Ragsdale DS (2002) Functional modulation of human brain Nav1.3 sodium channels, expressed in mammalian cells, by auxiliary beta 1, beta 2 and beta 3 subunits. Neuroscience 114:745-753.

Nicot A, Ratnakar PV, Ron Y, Chen CC, Elkabes S (2003) Regulation of gene expression in experimental autoimmune encephalomyelitis indicates early neuronal dysfunction. Brain 126:398-412.

Patino GA, Claes LRF, Lopez-Santiago LF, Slat EA, Dondeti RSR, Chen C, O’Malley HA, Gray CBB, Miyazaki H, Nukina N, Oyama F, De Jonghe P, Isom LL (2009) A functional null mutation of SCN1B in a patient with Dravet syndrome. J Neurosci 29:10764-10778.

Qu Y, Curtis R, Lawson D, Gilbride K, Ge P, DiStefano PS, Silos-Santiago I, Catterall WA, Scheuer T (2001) Differential modulation of sodium channel gating and persistent sodium currents by the beta1, beta2, and beta3 subunits. Mol Cell Neurosci 18:570-580.

Ragsdale DS, Avoli M (1998) Sodium channels as molecular targets for antiepileptic drugs. Brain Res Brain Res Rev 26:16-28.

Remy S, Gabriel S, Urban BW, Dietrich D, Lehmann TN, Elger CE, Heinemann U, Beck H (2003) A novel mechanism underlying drug resistance in chronic epilepsy. Ann Neurol 53:469-479. 
Rogawski MA, Löscher W (2004) The neurobiology of antiepileptic drugs for the treatment of nonepileptic conditions. Nat Med 10:685692.

Royeck M, Horstmann MT, Remy S, Reitze M, Yaari Y, Beck H (2008) Role of axonal Nav1.6 sodium channels in action potential initiation of cal pyramidal neurons. J Neurophysiol 100:2361-2380.

Sashihara S, Greer CA, Oh Y, Waxman SG (1996) Cell-specific differential expression of $\mathrm{Na}^{+}$-channel $\beta 1$-subunit mRNA in the olfactory system during postnatal development and after denervation. J Neurosci 16:702-713.

Schaub C, Uebachs M, Beck H (2007) Diminished response of CA1 neurons to antiepileptic drugs in chronic epilepsy. Epilepsia 48:1339-1350.

Sekerli M, Del Negro CA, Lee RH, Butera RJ (2004) Estimating action po- tential thresholds from neuronal time-series: new metrics and evaluation of methodologies. IEEE Trans Biomed Eng 51:1665-1672.

Toib A, Lyakhov V, Marom S (1998) Interaction between duration of activity and time course of recovery from slow inactivation in mammalian brain $\mathrm{Na}^{+}$channels. J Neurosci 18:1893-1903.

Vervaeke K, Hu H, Graham LJ, Storm JF (2006) Contrasting effects of the persistent $\mathrm{Na}^{+}$current on neuronal excitability and spike timing. Neuron 49:257-270.

Xu R, Thomas EA, Gazina EV, Richards KL, Quick M, Wallace RH, Harkin LA, Heron SE, Berkovic SF, Scheffer IE, Mulley JC, Petrou S (2007) Generalized epilepsy with febrile seizures plus-associated sodium channel beta1 subunit mutations severely reduce beta subunit-mediated modulation of sodium channel function. Neuroscience 148:164-174. 